Review

\title{
Lateral order in gel, subgel and crystalline phases of lipid membranes: Wide-angle X-ray scattering
}

\author{
Derek Marsh* \\ Max-Planck-Insitut für biophysikalische Chemie, 37077 Göttingen, Germany
}

\section{A R T I C L E I N F O}

\section{Article history:}

Received 16 September 2011

Received in revised form 31 October 2011

Accepted 3 November 2011

Available online 11 November 2011

\section{Keywords:}

Wide-angle

$\mathrm{X}$-ray diffraction

WAXS

Chain packing

Short spacing

Sublattice

Headgroup spacing

\begin{abstract}
A B S T R A C T
The chain packing in ordered phases of lipid bilayers can be classified according to wide-angle X-ray diffraction (WAXS). For triclinic $\left(\mathrm{T}_{\|}\right)$and monoclinic $\left(\mathrm{M}_{\|}\right)$packing in crystalline $\mathrm{L}_{\mathrm{c}}$ phases, the wide-angle reflections index on an oblique lattice with spacings $s_{10} \neq s_{01} \neq s_{11}$, and each chain has four nearest neighbours. For orthorhombic $\left(\mathrm{O}_{\perp}\right)$ packing in $\mathrm{L}_{c}$ phases, and the rotationally symmetric equivalent in metastable low-temperature $\mathrm{L}_{\beta}$ phases $\left(m \mathrm{~L}_{\beta}\right)$, the wide-angle reflections index on a centred rectangular lattice with spacings $s_{20}<s_{11}$, and each chain has four nearest neighbours. For distorted hexagonal packing in the $\mathrm{L}_{\mathrm{c}^{\prime}}$ subgel, and in $\mathrm{L}_{\beta^{\prime}}$ gel phases and the metastable low-temperature equivalent $\left(m \mathrm{~L}_{\beta^{\prime}}\right)$, the wide-angle reflections index on a centred rectangular lattice with spacings $s_{20}>s_{11}$, and each chain has two nearest neighbours. For hexagonal packing in the $\mathrm{L}_{\beta}, \mathrm{P}_{\beta^{\prime}}$ and interdigitated $\mathrm{L}_{\beta}^{\mathrm{i}}$ gel phases, the wide-angle reflections index on a centred rectangular lattice with spacings $s_{20}=s_{11}$, and each chain has six nearest neighbours. The available WAXS database for phospholipid and glycolipid bilayers is classified here according to the above scheme, by using well-established examples to assign the wide-angle reflections. The nearest and next-nearest neighbour chain-chain spacings, $a_{c h}$ and $b_{c h}$, and the cross-sectional area per chain, $A_{c h}$, are calculated for each phase of each lipid. These parameters determine many of the properties of the ordered lipid phases and, together with the chain tilt, specify the area occupied by the lipid head groups at the surface of the bilayer.
\end{abstract}

\section{Contents}

1. Introduction....

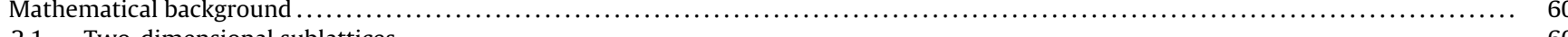

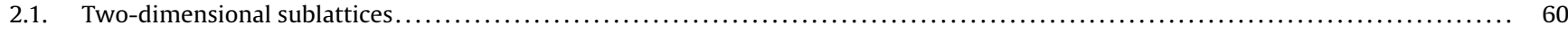

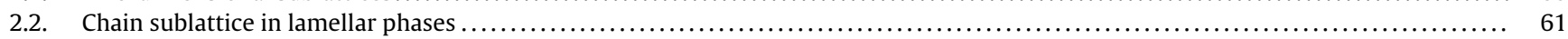

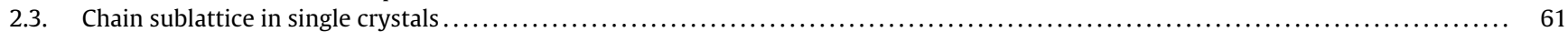

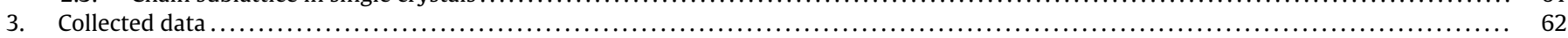

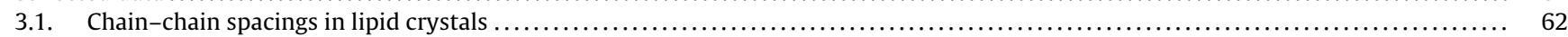

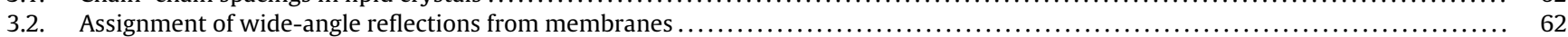

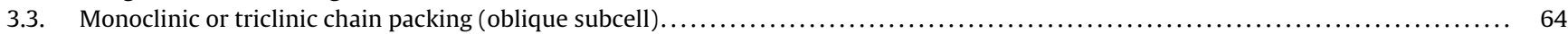

Abbreviations: (n:0) 2 PC, 1,2-diacyl-sn-glycero-3-phosphocholine; (12:0/18:0)PC, 1-lauroyl-2-stearoyl-sn-glycero-3-phosphocholine; 1,3-(18:0/14:0)PC, 1-stearoyl-3-

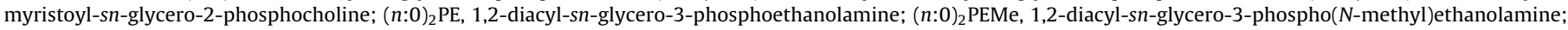

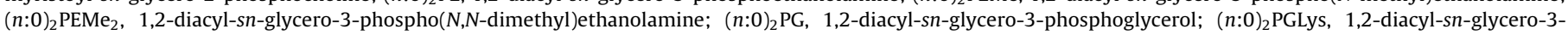

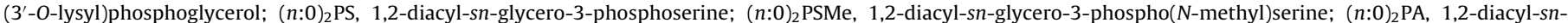

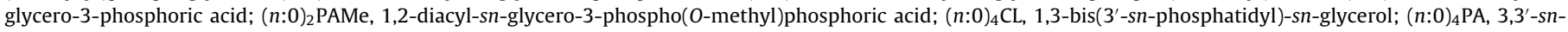

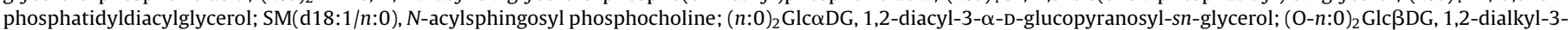

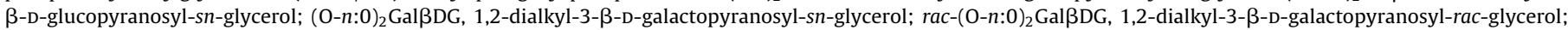

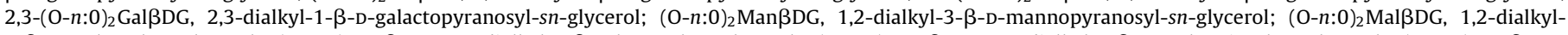

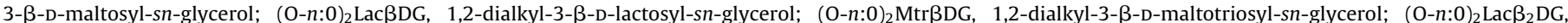

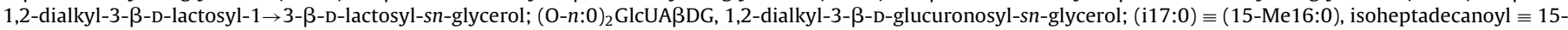
methylhexadecanoyl et seq.; 2-Me13:0, 2-methyltridecanoyl et seq.; 2-Ttd160, 2-tetradecylpalmitoyl.

* Tel.: +49 5512011285; fax: +49 5512011501.

E-mail address: dmarsh@gwdg.de 
3.4. Orthorhombic chain packing (centred rectangular subcell; $4 \mathrm{nn}$ )....

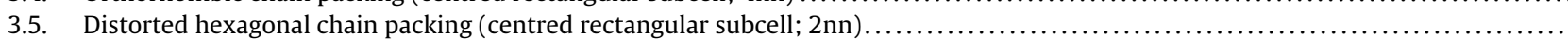

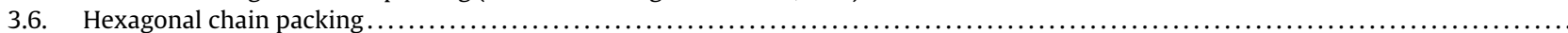

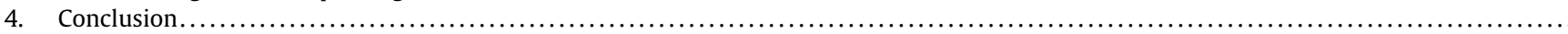

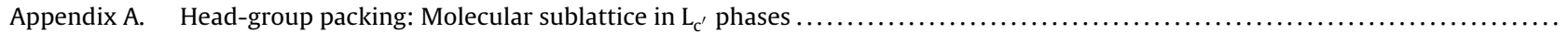

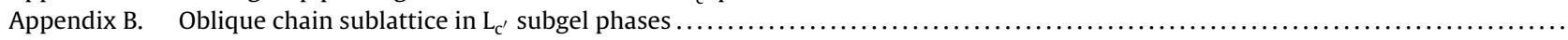

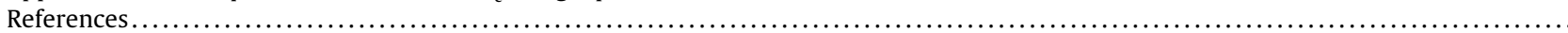

\section{Introduction}

Below the chain-melting transition, fully hydrated lipid bilayers assume gel $\left(\mathrm{L}_{\beta}, \mathrm{L}_{\beta^{\prime}}\right.$ or $\left.\mathrm{P}_{\beta^{\prime}}\right)$, subgel $\left(\mathrm{L}_{\mathrm{c}^{\prime}}\right)$, or quasi-crystalline $\left(\mathrm{L}_{\mathrm{c}}\right)$ phases. In all these phases, the lipid chains are in an ordered, nearly all-trans configuration but differ in their packing density, dynamics and rotational order. The rod-like chains are arranged in a two-dimensional lattice, which gives rise to wide-angle X-ray reflections in the $1 / 0.44$ to $1 / 0.36 \mathrm{~nm}^{-1}$ range that are determined by the particular lattice and packing density. The symmetry of the chain subcell depends on the specific lipid phase. Hexagonal lattices, in which a lipid chain has six nearest neighbours, are found in the $\mathrm{L}_{\beta}$ and $\mathrm{P}_{\beta^{\prime}}$ phases and the interdigitated gel phase, $\mathrm{L}_{\beta}^{\mathrm{i}}$. A distorted hexagonal lattice, with two nearest neighbours, is found in the $\mathrm{L}_{\beta^{\prime}}$ gel phase and $\mathrm{L}_{\mathrm{c}^{\prime}}$ subgel phase. In the $\mathrm{L}_{\mathrm{c}}$ phases, the chain sublattice is either orthorhombic, triclinic or monoclinic with four nearest neighbours, as in crystalline $n$-alkanes. The metastable $\mathrm{L}_{\beta}$ phase $\left(m L_{\beta}\right.$, see below), which is formed reversibly at low temperatures, also has an orthorhombic chain subcell.

The subgel phase of phosphatidylcholines (designated $\mathrm{L}_{\mathrm{c}^{\prime}}$, with a prime because the chains are tilted) is the most ordered lamellar phospholipid phase that is not actually a three-dimensional crystal. Wide-angle reflections from the $\mathrm{L}_{\mathrm{c}^{\prime}}$ phase are essentially independent of water content (i.e., of lamellar repeat distance), indicating that the lateral order is not correlated between bilayers (Ruocco and Shipley, 1982a). Phosphatidylethanolamines and many glycolipids, on the other hand, form stable low-temperature phases, $\mathrm{L}_{\mathrm{c}}$, that are true - largely dehydrated - three-dimensional lamellar crystals (see, e.g., Seddon et al., 1983; Mannock et al., 2007). In these cases, the chains pack in one of the two-dimensional modes characterised for crystalline hydrocarbons: principally centred rectangular (orthorhombic) or oblique (triclinic and monoclinic), or some hybrid of these types (Abrahamsson et al., 1978). The subgel or crystalline lamellar phases are formed only after prolonged incubation in the low-temperature regime. Immediate cooling of phospholipid gel-phases reversibly produces a metastable gel phase, $m \mathrm{~L}_{\beta^{\prime}}$ or $m \mathrm{~L}_{\beta}$, that is thought to be an intermediate on the pathway to the subgel phase (Tenchov et al., 2001). This transformation occurs at the so-called Y-transition, which is most marked for phosphatidylethanolamines because the lateral chain lattice changes from hexagonal to centred-rectangular symmetry (Tenchov et al., 1999; Harlos, 1978).

A distinguishing feature of the subgel phase (and $\mathrm{L}_{c}$ phases), is the appearance of X-ray reflections in the mid-to-wide angle range that are characteristic of the ordering of entire lipid molecules, i.e., of the head groups (Katsaras et al., 1995). In contrast, only reflections characteristic of lipid chain ordering are found in the wide-angle region of gel phases, because the lipid headgroups are rotationally disordered.

The properties of the ordered lipid phases are determined largely by the nearest and next-nearest neighbour chain-chain spacings (and their relative directions). Together with the chain tilt, these spacings also specify the area occupied by the lipid headgroups at the surface of the bilayer, which is a further determining factor that controls the bilayer assembly. In the following, I attempt to summarise the available data from wide-angle
X-ray scattering (WAXS) for phospholipid and glycolipid bilayers, in terms of the fundamental chain-chain spacings and area per chain. In most cases, the chain spacings are not reported fully in the original literature. Also, frequently the wide-angle reflections are not assigned. Advances in the latter direction help to do this for previously unassigned data. Sun et al. (1994) have made a detailed analysis of the wide-angle data for the $\mathrm{L}_{\beta^{\prime}}$ phase of phosphatidylcholines, as have Katsaras et al. (1995) for the $\mathrm{L}_{\mathrm{c}^{\prime}}$ subgel phase. Already mentioned is the recognition of different chain packing in the metastable $m \mathrm{~L}_{\beta}$ or $m \mathrm{~L}_{\beta^{\prime}}$ gel phases, below the "Y-transition" of phosphatidylethanolamines and phosphatidylcholines (Tenchov et al., 1999, 2001). In addition, triclinic or monoclinic chain packing has been identified in $\mathrm{L}_{c}$ phases of certain glycolipids (Mannock et al., 2007). All of these developments are used here for classifying and analyzing the complete dataset.

Note that, with the exception of single crystals, the data here all refer to fully hydrated bilayer membranes in excess water. However, the degree of hydration can differ considerably between the different ordered lipid phases. It is greatest for the gel phases of a particular lipid and least for the quasi-crystalline phases. True $L_{c}$ phases consist of a dispersion of anhydrous (or nearly so) crystals in excess water.

\section{Mathematical background}

\subsection{Two-dimensional sublattices}

The lateral ordering of the lipid chains or head groups can be described in terms of two-dimensional sublattices, with lattice vectors $\mathbf{a}_{s}$ and $\mathbf{b}_{s}$. The Laue equations for the scattering vectors, $\mathbf{q}$, that correspond to observable reflections are then:

$q \cdot a_{s}=h$

$q \cdot b_{s}=k$

where $h$ and $k$ are integer coordinates in reciprocal space, which correspond to the Miller indices of the scattering planes. Note that the conventional factor of $2 \pi$ is omitted from this definition of the scattering vector.

For the various two-dimensional lattices (see Fig. 1), the lengths $\left(q_{h k}\right)$ of the reciprocal lattice vectors are as follows:

oblique lattice:

$q_{h k}=\frac{1}{s_{h k}}=\frac{\sqrt{h^{2} b_{s}^{2}+k^{2} a_{s}^{2}-2 h k a_{s} b_{s} \cos \gamma_{s}}}{a_{s} b_{s} \sin \gamma_{s}}$

rectangular lattice $\left(\gamma_{s}=90^{\circ}\right)$ :

$q_{h k}=\frac{1}{s_{h k}}=\frac{\sqrt{h^{2} b_{s}^{2}+k^{2} a_{s}^{2}}}{a_{s} b_{s}}$

(for a centred rectangular lattice, $h+k$ is even)

hexagonal lattice $\left(a_{s}=b_{s}, \gamma_{s}=120^{\circ}\right)$ :

$q_{h k}=\frac{1}{s_{h k}}=\frac{(2 / \sqrt{3}) \sqrt{h^{2}+k^{2}+h k}}{a_{s}}$

where $s_{h k}$ are the spacings between adjacent scattering planes in real space, and $\gamma_{s}$ is the angle between the unit-cell axes. Note 


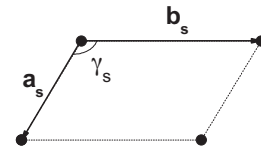

$\bullet$ oblique

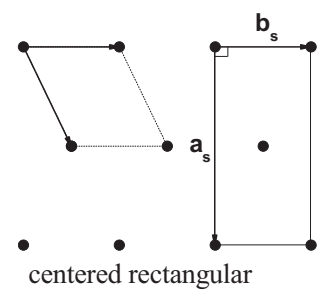

$b_{\mathrm{s}}$

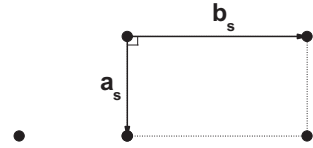
primitive rectangular

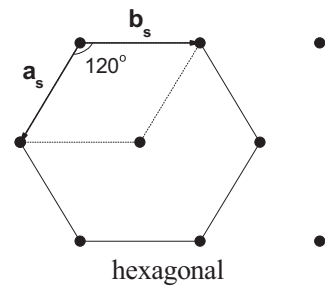

These expressions are appropriate to the $\mathrm{L}_{\beta}$ phases of phosphatidylethanolamines and glycosyl dialkylglycerols, and to the $\mathrm{P}_{\beta^{\prime}}$ phases of phosphatidylcholines and phosphatidylglycerols, which are often characterised by approximately hexagonal chain packing.

For $\mathrm{L}_{c}$ phases where the chain packing is triclinic $\left(\mathrm{T}_{\|}\right)$or monoclinic $\left(\mathrm{M}_{\|}\right)$, with a single chain per unit cell, the chain sublattice is truly oblique (see Fig. 1). In this case, at least three reflections $\left(s_{10}, s_{01}\right.$ and $\left.s_{11}\right)$ are required to specify the lattice parameters. The chain-chain spacings are then given directly by the dimensions of the primitive unit cell, i.e., $a_{c h} \equiv a_{s}, b_{c h} \equiv b_{s}$ and $\gamma_{c h} \equiv \gamma_{s}$. From Eq. (3), the lengths of the lattice vectors and their mutual inclination are:

$a_{c h}=\frac{s_{10}}{\sin \gamma_{c h}}$

$b_{c h}=\frac{s_{01}}{\sin \gamma_{c h}}$

$\cos \gamma_{c h}=\frac{1}{2}\left(\frac{s_{10}}{s_{01}}+\frac{s_{01}}{s_{10}}-\frac{s_{10} s_{01}}{s_{11}^{2}}\right)$

Fig. 1. Two-dimensional lattices that characterise the chain packing in lipid gel, subgel and crystalline lamellar phases. The chain sublattice is either hexagonal or centred-rectangular in gel and subgel phases, and oblique or centred-rectangular in crystalline $L_{c}$ phases. No chain subcell is primitive-rectangular, but the head-group (molecular) lattice in subgel phases may approximate to this.

that the short spacings of the chain and head-group sublattices are denoted here by $s_{h k}$ to distinguish them from the long spacings, $d_{h k}$, that are used to characterise the lamellar period, ripple period and the lattice periodicities of hexagonal and cubic phases.

\subsection{Chain sublattice in lamellar phases}

For orthorhombic or distorted hexagonal chain packing, the chain sublattice is centred rectangular (see Fig. 2), which is nonprimitive. One of the immediate-neighbour chain-chain spacings, $b_{c h}$, simply lies along the unit-cell $\mathbf{b}_{s}$-axis, and from Eq. (4) is given by:

$b_{c h} \equiv b_{s}=\frac{s_{11}}{\sqrt{1-\left(s_{11} / 2 s_{20}\right)^{2}}}$

The other chain spacing, $a_{c h}$, is given by the semidiagonal of the centred-rectangular unit cell:

$a_{c h}=\left(\frac{s_{20}}{s_{11}}\right) b_{c h}=\frac{s_{20}}{\sqrt{1-\left(s_{11} / 2 s_{20}\right)^{2}}}$

There are two chains per centred-rectangular unit cell, and the area per chain in the plane perpendicular to the chain axis is given by:

$A_{c h}=s_{20} b_{c h}=\frac{s_{20} s_{11}}{\sqrt{1-\left(s_{11} / 2 s_{20}\right)^{2}}}$

The oblique angle of the chain primitive unit subcell is given correspondingly by:

$\cos \gamma_{c h}=-\frac{s_{11}}{2 s_{20}}$

which reduces to $\gamma_{c h}=120^{\circ}$ for a hexagonal lattice. Eqs. (6)-(8) are used to obtain chain separations and cross-sectional areas in the $\mathrm{L}_{\beta^{\prime}}$, $m \mathrm{~L}_{\beta^{\prime}}$ and $\mathrm{L}_{\mathrm{C}^{\prime}}$ phases that have distorted-hexagonal chain packing, and in the $m \mathrm{~L}_{\beta}$ and $\mathrm{L}_{c}$ phases that have orthogonal chain packing with four nearest neighbours.

For a hexagonal chain sublattice: $s_{11}=s_{20}$, and the chain-chain spacings and area per chain become:

$a_{c h}=b_{c h}=\frac{2 s_{20}}{\sqrt{3}}$

$A_{c h}=\frac{2 s_{20}^{2}}{\sqrt{3}}$
The area per chain is equal to the area of the oblique unit cell and is given by:

$A_{c h}=a_{c h} b_{c h} \sin \gamma_{c h}=\frac{s_{10} s_{01}}{\sin \gamma_{c h}}$

which also can be determined with the help of Eq. (14).

Note that, unlike the monoclinic case, the $s_{10}, s_{01}$ and $s_{11}$ reflections from triclinic systems yield chain-chain spacings that are not perpendicular to the chain axis. The chain tilt, $\theta_{t}$, and its direction $(\omega)$, are then needed to convert the values of $a_{c h}, b_{c h}$ and $A_{c h}$ to the true values that correspond to the chain cross-sections. Triclinic $\left(\mathrm{T}_{\|}\right)$chain subcells in lipid crystals are considered in the section immediately following, where the true chain spacings and cross-sectional area are derived directly from the crystal lattice parameters.

Experiments with aligned subgel phases of phosphatidylcholines reveal that the chain packing in these $\mathrm{L}_{\mathrm{c}^{\prime}}$ phases is slightly oblique, but this is not resolved in powder diffraction. Further details are given in Appendix B.

\subsection{Chain sublattice in single crystals}

For a crystalline lipid, the lattice vectors of the triclinic (or monoclinic) hydrocarbon subcell have lengths $a_{s}, b_{s}$ and $c_{s}$, and mutual angles $\alpha_{s}, \beta_{s}$ and $\gamma_{s}$, where $\mathbf{a}_{s}$ and $\mathbf{b}_{s}$ specify the lateral chain packing, and $c_{s}$ defines translations between equivalent positions along the chain axis (Abrahamsson et al., 1978). The chain-chain spacings orthogonal to the $c_{s}$-axis are then specified by:

$a_{c h}=a_{s} \sin \beta_{s}$

$b_{c h}=b_{s} \sin \alpha_{s}$

because there is only one chain per triclinic $\left(T_{\|}\right)$, or monoclinic $\left(M_{\|}\right)$, hydrocarbon subcell. The inclination between these chain vectors is given by:

$\cos \gamma_{c h}=\frac{\cos \gamma_{s}-\cos \alpha_{s} \cos \beta_{s}}{\sin \alpha_{s} \sin \beta_{s}}$

The cross-sectional area per chain is correspondingly:

$A_{c h}=a_{c h} b_{c h} \sin \gamma_{c h}$

$$
=a_{s} b_{s} \sqrt{\sin ^{2} \alpha_{s} \sin ^{2} \beta_{s}-\left(\cos \gamma_{s}-\cos \alpha_{s} \cos \beta_{s}\right)^{2}}
$$

for $\mathrm{T}_{\|}$subcells, which requires knowledge of all three triclinic angles. Note that for monoclinic packing modes $\left(\alpha_{S}=\beta_{s}=90^{\circ}\right)$, the chain spacings and cross-section correspond directly with the $\mathrm{M}_{\|}$ 


$$
a_{c h}=b_{c h}
$$

6 nearest neighbours

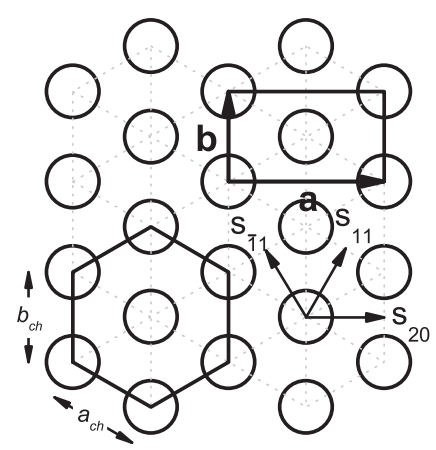

hexagonal
$\left(\mathrm{L}_{\beta} / \mathrm{P}_{\beta} / \mathrm{L}_{\beta}^{i}\right)$

$$
a_{c h}<b_{c h}
$$

4 nearest neighbours

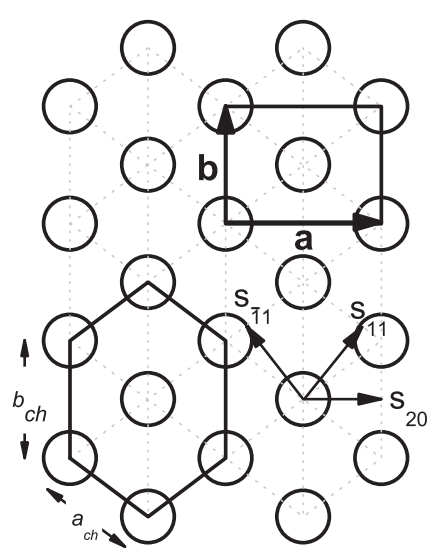

orthorhombic

$\left(m L_{\beta}\right)$

$$
a_{c h}>b_{c h}
$$

2 nearest neighbours
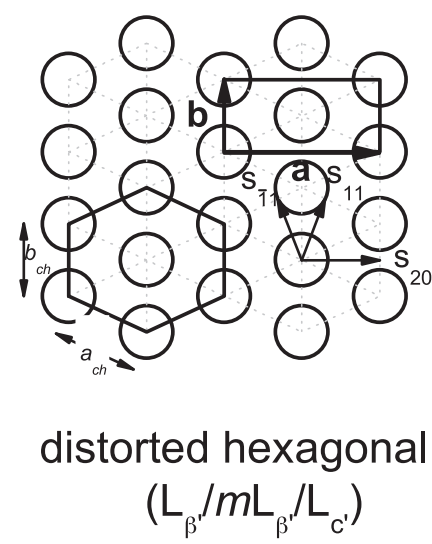

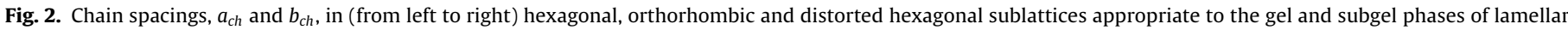
lipids. The chains have 6,4 and 2 nearest neighbours, respectively, and may be tilted in the direction of the nearest neighbours.

subcell: $a_{c h}=a_{s}$ and $b_{c h}=b_{s}$, and the inclination between chain vectors is $\gamma_{c h}=\gamma_{s}$.

For orthorhombic packing modes in crystals, the $\mathrm{O} \perp$ subcell is non-primitive (Abrahamsson et al., 1978). One of the chain-chain spacings is given directly by the $\mathbf{b}_{s}$-axis (see Fig. 2):

$b_{c h}=b_{s}$

The other chain-chain spacing is given by the semidiagonal of the centred-rectangular subcell:

$a_{c h}=\frac{\sqrt{a_{s}^{2}+b_{s}^{2}}}{2}$

The oblique angle between the $a_{c h}$ and $b_{c h}$ vectors is given by:

$\tan \gamma_{c h}=\frac{-a_{s}}{b_{s}}$

and the cross-sectional area per chain is simply:

$A_{c h}=\frac{a_{s} b_{s}}{2}$

because there are two chains per orthorhombic $\mathrm{O} \perp$ subcell. Note that the definitions of the $\mathbf{a}_{s}$ and $\mathbf{b}_{s}$ subcell axes have been interchanged, relative to the convention used for crystalline lipids in Abrahamsson et al. (1978), in order to correspond with that used above for the lipid bilayer systems (see Fig. 2).

\section{Collected data}

\subsection{Chain-chain spacings in lipid crystals}

As a preliminary, I summarise the data on chain spacings from lipids for which the molecular structures have been determined from X-ray diffraction of single crystals. These crystals are all lamellar but are either anhydrous or contain only one or two waters (or other solvate molecules) of crystallisation. Table 1 lists the chain-chain spacings, interchain angles and chain cross-sectional areas according to the different chain subcells: triclinic $\left(\mathrm{T}_{\|}\right)$, monoclinic $\left(\mathrm{M}_{\|}\right)$, orthorhombic $(\mathrm{O} \perp)$ and hybrid (HS1-4). These values are obtained from the subcell lattice parameters by using Eqs.
(16)-(23). Mostly, it is found that the two-chain lipids are somewhat less tightly packed than the single-chain lipids, the smallest area per chain being $0.182 \mathrm{~nm}^{2}$ for both $\mathrm{T}_{\|}$and $\mathrm{O} \perp$ subcells. The closest chain-chain spacing is $a_{c h}=0.397 \mathrm{~nm}$, for the triclinic $\mathrm{T}_{\|}$subcell, but this is balanced by a larger value of $b_{c h}=0.535 \mathrm{~nm}$, whereas the two chain-chain spacings in orthorhombic subcells are more comparable to one another: $a_{c h}=0.493 \mathrm{~nm}$ and $b_{c h}=0.445 \mathrm{~nm}$ for the closest spacings. These values for crystalline lipids set limits on the closest chain spacings that may be expected in $\mathrm{L}_{c}$ phases of lipid bilayer membranes.

\subsection{Assignment of wide-angle reflections from membranes}

It is useful first to summarise the different modes of chain packing in the gel and quasi-crystalline phases of lipid bilayer membranes. Not all find a counterpart in the crystal structures of membrane lipids (cf. Table 1 ). Hexagonal chain packing with six nearest neighbours (Fig. 2 left) is found in the $\mathrm{L}_{\beta}$ gel phase with untilted chains, in the $\mathrm{P}_{\beta^{\prime}}$ intermediate gel phase that has tilted chains and rippled bilayers, and in the $\mathrm{L}_{\beta}^{\mathrm{i}}$ gel phases with fully interdigitated chains. Hexagonal packing is not found in lipid crystals, but does occur in the $\mathrm{R}_{\mathrm{II}}$-rotator phase of longer $n$-alkanes (Denicolo et al., 1983; Small, 1986). The familiar $\mathrm{L}_{\beta^{\prime}}$ gel phase with tilted chains has orthogonal chain packing with two nearest neighbours (2nn; Fig. 2, right); this is designated here as distorted hexagonal packing (cf. Tardieu et al., 1973). The distorted hexagonal packing mode with two nearest neighbours is not found in lipid crystals, but is found (with a greater degree of distortion than in $\mathrm{L}_{\beta^{\prime}}$ ) in the low-temperature metastable $m \mathrm{~L}_{\beta^{\prime}}$ gel phase and in the stable subgel $\mathrm{L}_{\mathrm{c}^{\prime}}$ phase, both with tilted chains. Orthorhombic chain packing with four nearest neighbours ( $4 \mathrm{nn}$; Fig. 2, middle) is found in the low-temperature metastable $m \mathrm{~L}_{\beta}$ gel phase with untilted chains. This is the rotationally symmetric equivalent of the $\mathrm{O} \perp$ chain packing mode of lipid crystals that is found in the $\mathrm{R}_{\mathrm{I}}$-rotator phase of shorter $n$-alkanes (Doucet et al., 1981; Small, 1986; Sirota et al., 1993). It is designated here simply as orthogonal chain packing, as apposed to the distorted hexagonal packing that is orthogonal but has two nearest neighbours. Orthorhombic and distorted hexagonal packing can be differentiated in wide-angle diffraction because 
Table 1

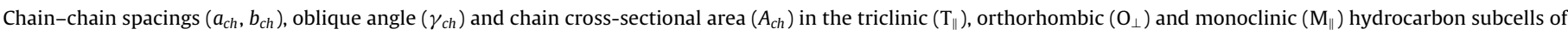
crystalline lipids. ${ }^{\mathrm{a}}$

\begin{tabular}{|c|c|c|c|c|c|c|}
\hline Lipid $^{b}$ & Subcell & $a_{c h}(\mathrm{~nm})$ & $b_{c h}(\mathrm{~nm})$ & $\gamma_{c h}\left(^{\circ}\right)$ & $A_{c h}\left(\mathrm{~nm}^{2}\right)$ & Ref. \\
\hline$n-\mathrm{C}_{18} \mathrm{H}_{38}$ & $\mathrm{~T}_{\|}$ & 0.5347 & 0.3967 & 120.7 & 0.1823 & 1 \\
\hline$(0-18: 0 / 0-1: 0) P C$ & $T_{\|}$ & 0.493 & 0.430 & 116 & 0.190 & 2 \\
\hline (16:0/0:0)PE & $T_{\|}$ & 0.498 & 0.412 & 114 & 0.187 & 3 \\
\hline$(14: 0)_{2} \mathrm{PA}$ & $T_{\|}$ & 0.480 & 0.424 & 114 & 0.186 & 4 \\
\hline (12:0/0:0)PA & $\mathrm{T}_{\|}$ & 0.485 & 0.425 & 112 & 0.191 & 5 \\
\hline (0-16:0)deoxyLPA1 & $T_{\|}$ & 0.473 & 0.403 & 108 & 0.182 & 6 \\
\hline (0-16:0)deoxyLPA2 & $T_{\|}$ & 0.475 & 0.406 & 108 & 0.184 & 6 \\
\hline Cer(t18:0/24:0) & $\mathrm{T}_{\|}$ & 0.489 & 0.428 & 116 & 0.188 & 7 \\
\hline (2-OH14:0)FA & $\mathrm{M}_{\|}$ & 0.474 & 0.430 & 110.9 & 0.190 & 8 \\
\hline (12:0)deoxyLPC & $\mathrm{M}_{\|}^{\prime \prime}$ & 0.507 & 0.413 & 110 & 0.197 & 9 \\
\hline$n-\mathrm{C}_{23} \mathrm{H}_{48}$ & $\mathrm{O}_{\perp}$ & 0.449 & 0.497 & 124 & 0.186 & 10 \\
\hline polyethylene & $\mathrm{O}_{\perp}$ & 0.445 & 0.493 & 124 & 0.182 & 11 \\
\hline$(12: 0)_{2} \mathrm{PEMe}_{2}$ & $\mathrm{O}_{\perp}$ & 0.457 & 0.499 & 123 & 0.191 & 12 \\
\hline$(12: 0)_{2} \mathrm{DG}$ & $\mathrm{O}_{\perp}$ & 0.451 & 0.488 & 123 & 0.185 & 13 \\
\hline Glc $\beta 1 \operatorname{Cer}(\mathrm{t18:0/0:0)}$ & $\mathrm{O}_{\perp}$ & 0.460 & 0.526 & 125 & 0.198 & 14 \\
\hline $\operatorname{Cer}\left(\mathrm{t} 18: 0 / 2,3(\mathrm{OH})_{2} 18: 0\right)$ & $\mathrm{O}_{\perp}$ & 0.447 & 0.503 & 124 & 0.186 & 15 \\
\hline TASp & $\mathrm{O}_{\perp}$ & 0.447 & 0.500 & 124 & 0.185 & 16 \\
\hline$(12: 0)_{2} \mathrm{PE}$ & $\mathrm{HS} 1^{\mathrm{c}}$ & 0.461 & 0.4975 & 123 & 0.193 & 17 \\
\hline$(16: 0)_{2} \mathrm{PE}$ & $\mathrm{HS}^{\mathrm{c}}$ & 0.462 & 0.502 & 123 & 0.195 & 18,19 \\
\hline Galß1Cer(d18:0/2(OH)18:0) & $\mathrm{HS} 2^{\mathrm{c}}$ & 0.47 & 0.46 & 111 & 0.200 & 20 \\
\hline$(14: 0)_{2} \mathrm{PG}$ & $\mathrm{HS}^{\mathrm{c}}$ & 0.432 & 0.505 & 118 & 0.192 & 21 \\
\hline$\left[\mathrm{Me}_{4}\right] \mathrm{Gal} \beta 1 \mathrm{Cer}(\mathrm{d} 18: 1 / 18: 0)$ & HS4 ${ }^{\mathrm{c}}$ & 0.475 & 0.425 & 114 & 0.184 & 22 \\
\hline
\end{tabular}

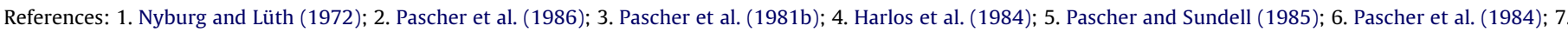

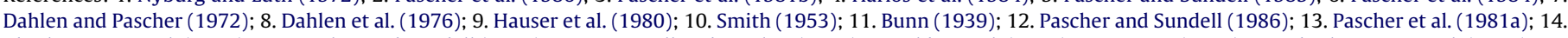

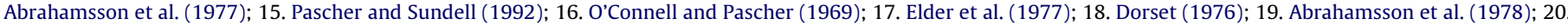
Pascher and Sundell (1977); 21. Pascher et al. (1987); 22. Nyholm et al. (1990).

a Data are calculated from the lattice parameters of the chain subcells that are given in the references quoted, by using Eqs. (16)-(23). Note that the definitions of the $\mathbf{a}_{\mathrm{s}}$ and $\mathbf{b}_{\mathrm{s}}$ subcell axes are interchanged, relative to those in Abrahamsson et al. (1978), so as to conform with Figs. 1 and 2.

b $(\mathrm{O}-18: 0 / 0-1: 0) \mathrm{PC}, \quad 1-(\mathrm{O}-18: 0)-2-(\mathrm{O}-1: 0)$ PtdCho.H ${ }_{2} \mathrm{O} ; \quad(16: 0 / 0: 0) \mathrm{PE}, \quad 1-(16: 0)-2-l y s o P t d E t n ; \quad(14: 0)_{2} \mathrm{PA}, \quad 1,2-(14: 0)_{2}$ Ptd; (12:0/0:0)PA, 1-(12:0)-2-lysoPtd; (O-

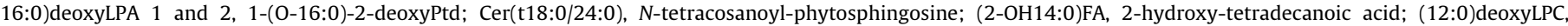

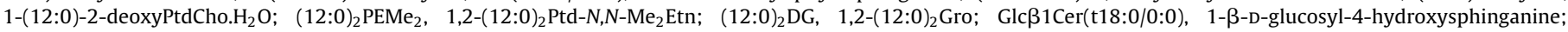

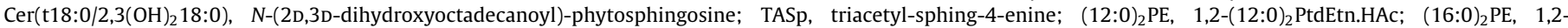

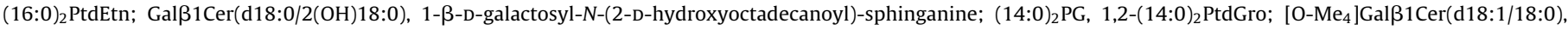
permethyl-1- $\beta$-D-galactosyl- $N$-octadecanoyl-sphing-4-enine.

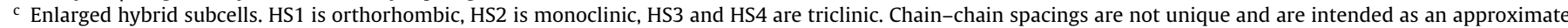
guide.

the degenerate (11) plus ( 11 ) reflection has twice the integrated intensity of the (20) reflection. For distorted hexagonal packing the spacings between the centred rectangular lattice planes are: $s_{11}=s_{\overline{1} 1}<s_{20}$, whereas for orthorhombic chain packing the short spacings are: $s_{11}=s_{\overline{1} 1}>s_{20}$.

Note that the $m \mathrm{~L}_{\beta^{\prime}}$ gel phase with tilted chains is referred to as SGII in Slater and Huang (1987) and Tenchov et al. (2001), and the $m \mathrm{~L}_{\beta}$ gel phase with untilted chains is referred to as $\mathrm{L}_{\mathrm{RI}}$ in Tenchov et al. (2001). Both phases are metastable at all temperatures of their existence and undergo conversion to the corresponding gel phase $\left(\mathrm{L}_{\beta^{\prime}}\right.$ or $\mathrm{L}_{\beta}$ respectively) at a temperature at which these are still metastable (Tenchov et al., 2001). The stable phase in this temperature range is the subgel phase, $\mathrm{L}_{\mathrm{c}^{\prime}}$, or a crystalline phase, $\mathrm{L}_{c}$, respectively.

The chains in $\mathrm{L}_{\mathrm{c}}$ phases can assume any of the packing modes, triclinic, monoclinic and orthogonal, that are found in the structures of lipid crystals (see Table 1 ). This includes the hybrid packing modes, HS, that contain elements of two of the basic $\mathrm{T}_{\|}, \mathrm{M}_{\|}$or $\mathrm{O} \perp$ chain subcells (Abrahamsson et al., 1978). Because the $L_{c}$ phases are 3-D crystals, many more wide-angle X-ray reflections are possible than in 2-D crystals, which can cause difficulties in identifying the primary reflections that are attributable to chain packing alone. For this reason, some of the $\mathrm{L}_{c}$ chain assignments are only tentative. The $\mathrm{L}_{\mathrm{c}^{\prime}}$ subgel phase, on the other hand, consists solely of 2-D crystals because adjacent bilayers are laterally uncorrelated. It is then possible to determine not only the chain sublattice but also the head-group sublattice for the subgel phase of phosphatidylcholines; further details are given in Appendix A.

The data on chain packing in lipid crystals given in Table 1 are some guide to assignment of diffraction from membrane systems where there is more than one wide-angle reflection and these are not assigned in the original publication. As already mentioned in the Introduction, assignments of wide-angle reflections have been given for $\mathrm{L}_{\beta^{\prime}}$ gel phases, $\mathrm{L}_{\boldsymbol{c}^{\prime}}$ subgel phases, the $m \mathrm{~L}_{\beta^{\prime}}$ and $m \mathrm{~L}_{\beta}$ metastable gel phases, and of some triclinic/monoclinic $\mathrm{L}_{\mathrm{c}}$ phases. All of these are invaluable help in suggesting assignments for other systems. The short spacings derived from wide-angle reflections in these standard systems are summarised in Table 2.

Oblique chain packing $\left(\mathrm{T}_{\|}\right.$or $\mathrm{M}_{\|}$subcells), which occurs only in $\mathrm{L}_{c}$ phases, has the broadest spread of observable wide-angle reflections, corresponding to the lattice spacings: $s_{10}=0.44-0.46 \mathrm{~nm}$ and $s_{11}=0.36-0.37 \mathrm{~nm}$, respectively. These two reflections are accompanied by a third which corresponds to an intermediate spacing: $s_{01}=0.4 \mathrm{~nm}$. The $\mathrm{L}_{\mathrm{C}^{\prime}}$ subgel phase of phosphatidylcholines has the next largest spread of observed wide-angle reflections, which corresponds to spacings of $s_{20}=0.44 \mathrm{~nm}$ and $s_{11}=0.38 \mathrm{~nm}$ for a centred rectangular lattice. In this case, however, a third reflection is expected at a spacing of $s_{02}=0.21 \mathrm{~nm}$ that is outside the range in which wide-angle reflections are conventionally registered. The metastable $\mathrm{L}_{\beta^{\prime}}$ phase of phosphatidylcholines $\left(m \mathrm{~L}_{\beta^{\prime}}\right)$ has reflections comparable to those of the $\mathrm{L}_{\mathrm{c}^{\prime}}$ phase, but of somewhat reduced range: $s_{20}=0.43 \mathrm{~nm}$ and $s_{11}=0.39-0.40 \mathrm{~nm}$. In orthorhombic $\mathrm{O} \perp$ subcells of crystalline hydrocarbons and the lowtemperature metastable $m \mathrm{~L}_{\beta}$ phases, which have untilted chains, the two-dimensional lattice is also centred rectangular but the total spread of the wide-angle reflections is less than for $L_{c^{\prime}}$ and $m \mathrm{~L}_{\beta^{\prime}}$ phases, corresponding to spacings of $s_{20}=0.37-0.39 \mathrm{~nm}$ and $s_{11}=0.41-0.42 \mathrm{~nm}$. Again, the third reflection is expected to lie outside the normal range $\left(s_{02}=0.25 \mathrm{~nm}\right)$. 
Table 2

Wide-angle X-ray reflections, $s_{h k}$, for different standard packing modes of lipid chains. $A_{c h}$ is the chain cross-sectional area.

\begin{tabular}{|c|c|c|c|c|c|}
\hline Mode or phase & $s_{10}\left(\text { or } s_{20}\right)^{\mathrm{a}}(\mathrm{nm})$ & $s_{01}\left(\text { or } s_{02}\right)^{\mathrm{a}}(\mathrm{nm})$ & $s_{11}(\mathrm{~nm})$ & $A_{c h}\left(\mathrm{~nm}^{2}\right)$ & Ref. \\
\hline $\mathrm{T}_{\|}\left(n-\mathrm{C}_{14} \mathrm{H}_{30}\right)$ & 0.461 & 0.403 & 0.359 & 0.182 & 1,2 \\
\hline $\mathrm{M}_{\|}(2-\mathrm{OH} 14: 0)$ & 0.443 & 0.402 & 0.370 & 0.190 & 3 \\
\hline $\mathrm{O} \perp\left(n-\mathrm{C}_{23} \mathrm{H}_{48}\right)$ & 0.374 & 0.249 & 0.414 & 0.186 & 4 \\
\hline$m \mathrm{~L}_{\beta}$ & $0.38-0.39$ & $(0.25)$ & 0.42 & $0.191-0.194$ & 5 \\
\hline $\mathrm{L}_{\mathrm{c}^{\prime}}$ & 0.44 & $(0.21)$ & 0.38 & 0.185 & 6 \\
\hline$m \mathrm{~L}_{\beta^{\prime}}$ & 0.43 & $(0.23)$ & $0.39-0.40$ & $0.188-0.194$ & 5 \\
\hline $\mathrm{L}_{\beta^{\prime}}$ & 0.424 & $(0.24)$ & 0.418 & 0.204 & 7 \\
\hline
\end{tabular}

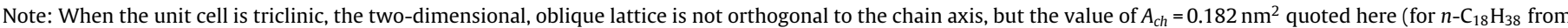

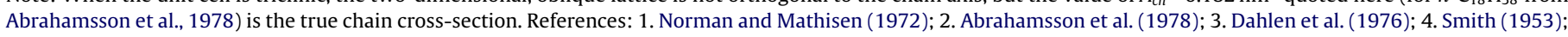
5. Tenchov et al. (2001); 6. Katsaras et al. (1995); 7. Sun et al. (1994). Where the $s_{02}$ reflection is given in parentheses, it is not observed or not reported.

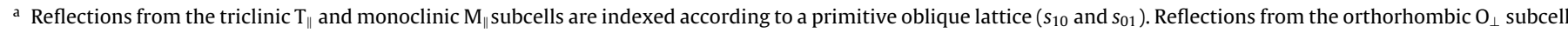
and all other systems are indexed according to a centred rectangular lattice $\left(s_{20}\right.$ and $\left.s_{02}\right)$.

Note that for orthorhombic packing, the $s_{11}$ spacing is the larger and each chain has four nearest neighbours, whereas for the $L_{c^{\prime}}$, $\mathrm{L}_{\beta^{\prime}}$ and $m \mathrm{~L}_{\beta^{\prime}}$ phases, the $s_{20}$ spacing is the larger, corresponding to a distorted hexagonal subcell with two nearest neighbours (see Fig. 2). In the latter case, the tilt is in the direction of nearest neighbours, which causes broadening of the (11) reflection. The tilted normal $\mathrm{L}_{\beta^{\prime}}$ gel phase of phosphatidylcholines is analogous to the $\mathrm{L}_{\mathrm{c}^{\prime}}$ and $m \mathrm{~L}_{\beta^{\prime}}$ phases but has a much smaller spread of wide-angle reflections: $s_{20}=0.424 \mathrm{~nm}$ and $s_{11}=0.418 \mathrm{~nm}$. Finally, the untilted $\mathrm{L}_{\beta}$ gel phase, the interdigitated $\mathrm{L}_{\beta}^{\mathrm{i}}$ gel phase, and the rippled $\mathrm{P}_{\beta^{\prime}}$ phase all have hexagonal chain packing with six nearest neighbours. This is characterised by a single reflection, which corresponds to the lattice spacing $s_{20}=s_{11}$, in the wide-angle region.

\subsection{Monoclinic or triclinic chain packing (oblique subcell)}

The close chain packing that is characteristic of the triclinic or monoclinic packing modes has been identified in the $\mathrm{L}_{c}$ phases of rac-(O-n:0) ${ }_{2}$ GalßDGs (Mannock et al., 2007). The chain subcells of several other monoglycosyl dialkylglycerols index on the same lattice. Table 3 gives the assignments of the wide-angle chain reflections $\left(s_{10}, s_{01}\right.$ and $\left.s_{11}\right)$ and the chain packing parameters deduced from the oblique 2D subcell. An arithmetical error in the original calculation for the $\mathrm{L}_{\mathrm{c} 1}$ phase of rac-(O-16:0) $)_{2}$ Gal $\beta D G$ is corrected in Table 3, which then gives a rather low area per chain. For the $\mathrm{L}_{\mathrm{c}}$ phase of (O-14:0) ${ }_{2}$ Glc $\beta$ DG, the third reflection at $0.356 \mathrm{~nm}$ found by Hinz et al. (1991) is not seen by Köberl et al. (1998) nor by Seddon et al. (2003) (Table 5 gives the indexing according to a distorted hexagonal lattice for the latter two cases.). For (0-16:0) ${ }_{2}$ Glc $\beta D G$, the fourth reflection of Hinz et al. (1991) at $0.337 \mathrm{~nm}$ is ignored. Only two reflections are reported for the $\mathrm{L}_{\mathrm{c}}$ phase of this lipid by Köberl et al. (1998).

For the methyl $\alpha$-branched alkyl-acyl phosphatidylcholine (0-16:0/2-Me13:0)PC, cooling from the fluid phase produces a gel phase with wide-angle reflections that are characteristic of oblique chain packing (Bringezu et al., 2001). Similar chain packing is found for the gel phases of $\alpha$-branched acyl-alkyl phosphatidylethanolamines (2-Me16:0/O-16:0)PE and (2-Me18:0/0-16:0)PE (Bringezu et al., 2000). Wide-angle X-ray data for these phospholipids are included in Table 3. The area per chain for these lipids is greater than for the glycolipids, because of the methyl branching.

\subsection{Orthorhombic chain packing (centred rectangular subcell; 4nn)}

Orthorhombic chain packing with four nearest neighbours is found at temperatures above the rotator $\left(R_{I}\right)$ transition of crystalline $n$-alkanes (Sirota et al., 1993), and in the orthorhombic $(\mathrm{O} \perp)$ chain subcell of lipid single crystals (see Table 1$)$. In hydrated lipid bilayers, orthorhombic packing ( $4 \mathrm{nn}$ ) has been identified below the metastable "Y-transition" in the $m \mathrm{~L}_{\beta}$ gel phase of phosphatidylethanolamines and certain other phospholipids (Harlos, 1978; Tenchov et al., 1999, 2001), in $\mathrm{L}_{c}$ phases of phosphatidylethanolamines (Seddon et al., 1983), galactosyl dialkylglycerols (Mannock et al., 2007) and at low temperature in the interdigitated gel phase of dialkyl phosphatidylcholine (Laggner et al., 1987). Table 4 gives the assignments of the wide-angle chain reflections $\left(s_{20}\right.$ and $\left.s_{11}\right)$ and the chain packing parameters deduced from the centred rectangular subcell.

Assignments of the wide-angle X-ray reflections for the $\mathrm{L}_{\mathrm{c}} 1$ and $\mathrm{L}_{\mathrm{c}} 2$ crystalline phases of $(14: 0)_{2}$ PE from Muluktla and Shipley (1984) are made on the basis of relative intensities, as indicated clearly for the $\mathrm{L}_{c}$-phase of this lipid in Tenchov et al. (2001). The wide-angle chain reflections from the $\mathrm{L}_{\mathrm{c}}$ phases of $\mathrm{N}$-methylated phosphatidylethanolamines (14:0) $)_{2} \mathrm{PEMe}$ and (14:0) ${ }_{2} \mathrm{PEMe}_{2}$ (from Muluktla and Shipley, 1984) are assigned similarly, on the basis of intensities and analogy with $(14: 0)_{2} \mathrm{PE}$. The data on chain packing in the $\mathrm{L}_{\mathrm{c}}$ phase of $(16: 0)_{2} \mathrm{PG}$ are modelled indirectly from the oblique head-group lattice: $\left(a=0.796 \mathrm{~nm}, b=0.550 \mathrm{~nm}, \gamma=100.5^{\circ}\right)$, by using dimensions from crystalline polyethylene (see Blaurock and McIntosh, 1986). Assignments of the chain reflections from the quasi-crystalline complexes of phosphatidylserine with lithium ions, $(14: 0)_{2}$ PS.Li and (16:0) $)_{2}$ PS.Li, are given in Table 4 on the basis of the intensity of the 11 plus $1 \overline{1}$ reflection and analogy with wellestablished cases of orthogonal packing.

Results for the $\mathrm{L}_{\mathrm{c} 2}$ phase of rac- $(0-14: 0)_{2} \mathrm{Gal} \beta \mathrm{DG}$ are revised in Table 4 from those in Mannock et al. (2007), which assumed $a^{*}=b^{*}$ that is valid only in the case of hexagonal packing for which $\gamma=120^{\circ}$ (see Fig. 1). In addition, the assignments for rac-(0-16:0) ${ }_{2}$ Gal $\beta D G$ are revised to correspond with those for $\mathrm{rac}-(\mathrm{O}-14: 0)_{2} \mathrm{Gal} \beta \mathrm{DG}$ (see Table 4).

The methyl-branched alkyl-acyl phosphatidylcholines (0-16:0/2-Me16:0)PC and (3-Me16:0/0-16:0)PC form lowtemperature phases that are probably metastable, and which for (3-Me16:0/0-16:0)PC is interdigitated (Förster et al., 1992). The relative intensities of the wide-angle X-ray reflections are consistent with orthorhombic chain packing of the $4 \mathrm{nn}\left(\mathrm{mL}_{\beta}\right)$ type, as is indicated in Table 4 which revises the assignments given in the original publication.

For $(18: 0)_{2} \mathrm{PG}$, an interdigitated phase with orthogonal chain packing, $\mathrm{L}_{\beta}^{\mathrm{i}}$, is observed at low temperatures (Pabst et al., 2007). This (possibly metastable) phase coexists with the normal $\mathrm{L}_{\beta^{\prime}}$ phase and transforms to an interdigitated phase with hexagonal chain packing at higher temperatures. It is not found in phosphatidylglycerols of shorter chain lengths. 
Table 3

Wide-angle reflections and subcell dimensions for $\mathrm{L}_{\mathrm{c}}$ phases with triclinic or monoclinic chain packing modes (oblique subcell).

\begin{tabular}{|c|c|c|c|c|c|c|c|c|c|c|}
\hline Lipid & Phase & $T\left({ }^{\circ} \mathrm{C}\right)$ & $s_{10}(\mathrm{~nm})$ & $s_{01}(\mathrm{~nm})$ & $s_{11}(\mathrm{~nm})$ & $a_{c h}(\mathrm{~nm})$ & $b_{c h}(\mathrm{~nm})$ & $\gamma_{c h}\left({ }^{\circ}\right)$ & $A_{c h}\left(\mathrm{~nm}^{2}\right)$ & $\overline{\text { Ref. }}$ \\
\hline$(\mathrm{O}-14: 0)_{2}$ Glc $\beta D G$ & $\mathrm{~L}_{\mathrm{c}}$ & 20 & 0.442 & 0.381 & 0.356 & 0.471 & 0.406 & 110 & 0.180 & 1 \\
\hline \multirow[t]{2}{*}{$(0-18: 0)_{2}$ Glc $\beta D G$} & \multirow[t]{2}{*}{$\mathrm{L}_{\mathrm{c}}$} & 20 & 0.441 & 0.383 & 0.367 & 0.477 & 0.415 & 113 & 0.183 & 1 \\
\hline & & 50 & 0.443 & 0.387 & 0.369 & 0.479 & 0.418 & 112 & 0.185 & 1 \\
\hline \multirow[t]{2}{*}{$(\mathrm{O}-12: 0)_{2}$ Gal $\beta D G$} & \multirow[t]{2}{*}{$\mathrm{L}_{\mathrm{c}}$} & 20 & 0.45 & 0.39 & 0.35 & 0.47 & 0.41 & 107 & 0.184 & 2 \\
\hline & & 55 & 0.45 & 0.43 & 0.39 & 0.48 & 0.46 & 111 & 0.208 & 2 \\
\hline \multirow[t]{4}{*}{$(0-14: 0)_{2}$ Gal $\beta D G$} & \multirow[t]{4}{*}{$\mathrm{L}_{\mathrm{c}}$} & 20 & 0.45 & 0.39 & 0.35 & 0.47 & 0.41 & 107 & 0.184 & 3 \\
\hline & & & 0.454 & 0.387 & 0.350 & 0.475 & 0.405 & 107 & 0.184 & 4 \\
\hline & & 40 & 0.451 & 0.392 & 0.348 & 0.470 & 0.408 & 106 & 0.184 & 2 \\
\hline & & 60 & 0.453 & 0.393 & 0.378 & 0.491 & 0.426 & 113 & 0.193 & 2 \\
\hline \multirow[t]{2}{*}{$(0-16: 0)_{2}$ Gal $\beta D G$} & \multirow[t]{2}{*}{$\mathrm{L}_{\mathrm{c}}$} & 20 & 0.45 & 0.39 & 0.35 & 0.47 & 0.41 & 107 & 0.184 & 2 \\
\hline & & 65 & 0.45 & 0.433 & 0.39 & 0.482 & 0.464 & 111 & 0.209 & 2 \\
\hline \multirow[t]{3}{*}{$(0-18: 0)_{2}$ Gal $\beta D G$} & \multirow[t]{3}{*}{$\mathrm{L}_{\mathrm{c}}$} & 20 & 0.447 & 0.382 & 0.346 & 0.468 & 0.400 & 107 & 0.179 & 1 \\
\hline & & & 0.45 & 0.39 & 0.35 & 0.47 & 0.41 & 107 & 0.184 & 2 \\
\hline & & 60 & 0.447 & 0.385 & 0.348 & 0.469 & 0.404 & 107 & 0.180 & 1 \\
\hline $2,3-(0-14: 0)_{2}$ Gal $\beta D G$ & $\mathrm{~L}_{\mathrm{c}}$ & 20 & 0.45 & 0.39 & 0.35 & 0.47 & 0.41 & 107 & 0.184 & 3 \\
\hline \multirow[t]{2}{*}{ rac- $(0-14: 0)_{2}$ Gal $\beta D G$} & \multirow[t]{2}{*}{$\mathrm{L}_{\mathrm{c} 1}$} & 20 & 0.44 & 0.38 & 0.34 & 0.46 & 0.40 & 107 & 0.175 & 5 \\
\hline & & & 0.45 & 0.39 & 0.35 & 0.47 & 0.41 & 107 & 0.184 & 3 \\
\hline rac- $(0-15: 0)_{2}$ Gal $\beta D G$ & $\mathrm{~L}_{\mathrm{c} 1}$ & 10 & 0.44 & 0.38 & 0.36 & 0.47 & 0.41 & 111 & 0.180 & 5 \\
\hline rac- $(0-16: 0)_{2}$ Gal $\beta D G$ & $\mathrm{~L}_{\mathrm{c} 1}$ & 0 & 0.43 & 0.38 & 0.34 & 0.45 & 0.40 & 108 & 0.171 & 5 \\
\hline \multirow[t]{2}{*}{$(0-16: 0 / 2-M e 13: 0) P C$} & \multirow[t]{2}{*}{$\mathrm{L}_{\beta^{\prime}}$} & 11 & 0.437 & 0.424 & 0.400 & 0.482 & 0.468 & 115 & 0.204 & 6 \\
\hline & & 15.5 & 0.439 & 0.426 & 0.402 & 0.484 & 0.470 & 115 & 0.206 & 6 \\
\hline (2-Me16:0/0-16:0)PE & $\mathrm{L}_{\beta^{\prime}}$ & 10 & 0.445 & 0.429 & 0.416 & 0.498 & 0.480 & 117 & 0.214 & 7 \\
\hline (2-Me18:0/0-16:0)PE & $\mathrm{L}_{\beta^{\prime}}$ & 47.4 & 0.444 & 0.429 & 0.410 & 0.493 & 0.476 & 116 & 0.211 & 7 \\
\hline
\end{tabular}

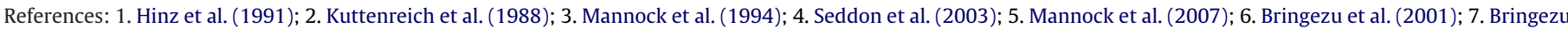
et al. (2000).

\subsection{Distorted hexagonal chain packing (centred rectangular subcell; 2nn)}

Distorted hexagonal chain packing (orthorhombic with two nearest neighbours) is the common mode of chain packing in the stable $\left(\mathrm{L}_{\beta^{\prime}}\right)$ and metastable $\left(m \mathrm{~L}_{\beta^{\prime}}\right)$ gel phases, and the $\mathrm{L}_{\mathrm{C}^{\prime}}$ subgel phases of diacyl phosphatidylcholines (Tardieu et al., 1973; Ruocco and Shipley, 1982a; Sun et al., 1994; Koynova et al., 1995; Tenchov et al., 2001; Katsaras et al., 1995) and of several other phospholipids (Jähnig et al., 1979; Watts et al., 1981; Tenchov et al., 2001; Lewis et al., 2007; Maulik and Shipley, 1995). Table 5 gives the assignments of the wide-angle chain reflections $\left(s_{20}\right.$ and $\left.s_{11}\right)$ and the chain packing parameters deduced from the centred rectangular subcell.

The chain reflections from the $\mathrm{L}_{\mathrm{c}^{\prime}}$ subgel phase of symmetrical and mixed-chain phosphatidylcholines, including the 1,3-isomers, from Stümpel et al. (1983) have been reassigned by Raghunathan

Table 4

Wide-angle reflections and subcell dimensions for $\mathrm{L}_{\mathrm{c}}$ and $m \mathrm{~L}_{\beta}$ phases with orthorhombic chain packing (centred-rectangular subcell; 4 nn).

\begin{tabular}{|c|c|c|c|c|c|c|c|c|c|}
\hline Lipid & Phase & $T\left({ }^{\circ} \mathrm{C}\right)$ & $s_{20}(\mathrm{~nm})$ & $s_{11}(\mathrm{~nm})$ & $a_{c h}(\mathrm{~nm})$ & $b_{c h}(\mathrm{~nm})$ & $\gamma_{c h}\left(^{\circ}\right)$ & $A_{c h}\left(\mathrm{~nm}^{2}\right)$ & Ref. \\
\hline$(20: 0 / 10: 0) P C$ & $\mathrm{~L}_{\mathrm{c}}$ & -30 & 0.37 & 0.41 & 0.44 & 0.49 & 124 & 0.182 & 1 \\
\hline$(22: 0 / 10: 0) \mathrm{PC}$ & $\mathrm{L}_{\mathrm{c}}$ & -30 & 0.37 & 0.41 & 0.44 & 0.49 & 124 & 0.182 & 1 \\
\hline (O-16:0/2-Me13:0)PC & $\mathrm{L}_{\mathrm{c}}$ & 8.5 & 0.390 & 0.435 & 0.470 & 0.524 & 124 & 0.204 & 2 \\
\hline$(12: 0)_{2} \mathrm{PE}$ & $\mathrm{L}_{\mathrm{c}}$ & 26 & 0.378 & 0.401 & 0.446 & 0.473 & 122 & 0.179 & 3 \\
\hline \multirow[t]{3}{*}{$(14: 0)_{2} \mathrm{PE}$} & $\mathrm{L}_{\mathrm{c}} 1$ & 2 & 0.369 & 0.456 & 0.469 & 0.580 & 128 & 0.214 & 4 \\
\hline & & 20 & 0.381 & 0.405 & 0.450 & 0.479 & 122 & 0.182 & 5 \\
\hline & $\mathrm{L}_{\mathrm{c}} 2$ & 43 & 0.379 & 0.421 & 0.456 & 0.506 & 124 & 0.192 & 4 \\
\hline$(14: 0)_{2}$ PEMe & $\mathrm{L}_{\mathrm{c}}$ & 2 & 0.375 & 0.405 & 0.446 & 0.481 & 123 & 0.180 & 4 \\
\hline$(14: 0)_{2} \mathrm{PEMe}_{2}$ & $\mathrm{~L}_{\mathrm{c}}$ & 2 & 0.380 & 0.409 & 0.451 & 0.485 & 123 & 0.184 & 4 \\
\hline$(14: 0)_{2} \mathrm{PG}$ & $\mathrm{L}_{\mathrm{c}}$ & 4 & 0.385 & 0.415 & 0.457 & 0.493 & 123 & 0.190 & 6 \\
\hline$(16: 0)_{2} \mathrm{PG}$ & $\mathrm{L}_{\mathrm{c}}$ & & 0.370 & 0.410 & 0.445 & 0.493 & 124 & 0.182 & 7 \\
\hline$(14: 0)_{2}$ PS.Li & $\mathrm{L}_{\mathrm{c}} \mathrm{I}$ & 20 & 0.393 & 0.418 & 0.464 & 0.494 & 122 & 0.194 & 8 \\
\hline$(16: 0)_{2}$ PS.Li & $\mathrm{L}_{\mathrm{c}} \mathrm{I}$ & 39 & 0.380 & 0.418 & 0.455 & 0.501 & 123 & 0.190 & 9 \\
\hline rac- $(\mathrm{O}-14: 0)_{2} \mathrm{Gal} \beta \mathrm{DG}$ & $\mathrm{L}_{\mathrm{c} 2}$ & 58 & 0.370 & 0.420 & 0.449 & 0.510 & 125 & 0.189 & 10 \\
\hline rac- $(0-16: 0)_{2}$ Gal $\beta D G$ & $\mathrm{~L}_{\mathrm{c} 2}$ & 0 & 0.360 & 0.403 & 0.434 & 0.486 & 124 & 0.175 & 10 \\
\hline$(24: 0)_{2} \mathrm{PC}$ & $m \mathrm{~L}_{\beta}$ & 25 & 0.373 & 0.414 & 0.448 & 0.498 & 124 & 0.186 & 11 \\
\hline (O-16:0/2-Me16:0)PC & $m \mathrm{~L}_{\beta}$ & -4.9 & 0.387 & 0.423 & 0.462 & 0.505 & 123 & 0.195 & 12 \\
\hline \multirow[t]{2}{*}{$(16: 0)_{2} \mathrm{PE}$} & $m \mathrm{~L}_{\beta}$ & -12 & 0.388 & 0.419 & 0.461 & 0.498 & 123 & 0.193 & 5 \\
\hline & & 0 & 0.396 & 0.418 & 0.466 & 0.492 & 122 & 0.195 & 5 \\
\hline \multirow[t]{2}{*}{$(18: 0)_{2} \mathrm{PE}$} & $m \mathrm{~L}_{\beta}$ & -12 & 0.381 & 0.418 & 0.456 & 0.500 & 123 & 0.190 & 5 \\
\hline & & 5 & 0.388 & 0.418 & 0.461 & 0.496 & 123 & 0.192 & 13 \\
\hline$(\mathrm{O}-14: 0)_{2} \mathrm{PE}$ & $m \mathrm{~L}_{\beta}$ & -4 & 0.394 & 0.413 & 0.463 & 0.485 & 122 & 0.191 & 14 \\
\hline$(\mathrm{O}-16: 0)_{2} \mathrm{PE}$ & $m \mathrm{~L}_{\beta}$ & -15 & 0.379 & 0.42 & 0.455 & 0.505 & 124 & 0.191 & 15 \\
\hline$(16: 0)_{2} \mathrm{PG}, \mathrm{pH} 1$ & $m \mathrm{~L}_{\beta}$ & -15 & 0.378 & 0.418 & 0.454 & 0.502 & 124 & 0.190 & 5 \\
\hline$(\mathrm{O}-14: 0)_{2} \mathrm{PA}$ & $m \mathrm{~L}_{\beta}$ & -3 & 0.387 & 0.414 & 0.458 & 0.490 & 122 & 0.190 & 14 \\
\hline$(\mathrm{O}-16: 0)_{2} \mathrm{PA}$ & $m \mathrm{~L}_{\beta}$ & 5 & 0.387 & 0.418 & 0.460 & 0.497 & 123 & 0.192 & 16 \\
\hline (3-Me16:0/0-16:0)PC & $m \mathrm{~L}_{\beta, \mathrm{I}}$ & -7 & 0.382 & 0.421 & 0.458 & 0.505 & 123 & 0.193 & 12 \\
\hline$(\mathrm{O}-16: 0)_{2} \mathrm{PC}$ & $\mathrm{L}_{\mathrm{o}}^{\mathrm{i}}$ & 0 & 0.380 & 0.420 & 0.456 & 0.504 & 124 & 0.191 & 17 \\
\hline$(18: 0)_{2} \mathrm{PG}$ & $\mathrm{L}_{\beta}^{\mathrm{i}}$ & 2 & 0.383 & 0.422 & 0.459 & 0.506 & 123 & 0.194 & 18 \\
\hline
\end{tabular}

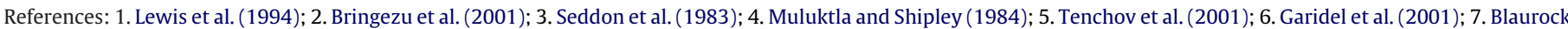

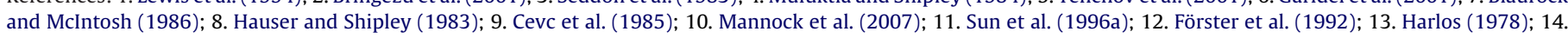
Harlos and Eibl (1981); 15. Tenchov et al. (1999); 16. Jähnig et al. (1979); 17. Laggner et al. (1987); 18. Pabst et al. (2007). 
Table 5

Wide-angle reflections and subcell dimensions for $\mathrm{L}_{\mathrm{c}^{\prime}}, m \mathrm{~L}_{\beta^{\prime}}$ and $\mathrm{L}_{\beta^{\prime}}$ phases with distorted hexagonal chain packing (centred-rectangular chain subcell; $2 \mathrm{nn}$ ).

\begin{tabular}{|c|c|c|c|c|c|c|c|c|c|}
\hline Lipid & Phase & $T\left({ }^{\circ} \mathrm{C}\right)$ & $s_{20}(\mathrm{~nm})$ & $s_{11}(\mathrm{~nm})$ & $a_{c h}(\mathrm{~nm})$ & $b_{c h}(\mathrm{~nm})$ & $\gamma_{c h}\left({ }^{\circ}\right)$ & $A_{c h}\left(\mathrm{~nm}^{2}\right)$ & Ref. \\
\hline$(14: 0)_{2} \mathrm{PC}$ & $\mathrm{L}_{\mathrm{C}^{\prime}}$ & -15 & 0.434 & 0.399 & 0.489 & 0.449 & 117 & 0.195 & 1 \\
\hline \multirow[t]{8}{*}{$(16: 0)_{2} \mathrm{PC}$} & $\mathrm{L}_{\mathrm{C}^{\prime}}$ & -2 & 0.440 & 0.387 & 0.490 & 0.431 & 116 & 0.190 & 2 \\
\hline & & 5 & 0.440 & 0.385 & 0.489 & 0.428 & 116 & 0.188 & 3 \\
\hline & & 5 & 0.440 & 0.388 & 0.490 & 0.432 & 116 & 0.190 & 4 \\
\hline & & 7 & 0.440 & 0.390 & 0.491 & 0.435 & 116 & 0.191 & 5,6 \\
\hline & & 8 & 0.443 & 0.383 & 0.491 & 0.425 & 116 & 0.188 & 7 \\
\hline & & 10 & 0.446 & 0.392 & 0.497 & 0.436 & 116 & 0.195 & 5,8 \\
\hline & & 10 & 0.440 & 0.390 & 0.491 & 0.435 & 116 & 0.191 & 9 \\
\hline & & $<13$ & 0.441 & 0.385 & 0.490 & 0.428 & 116 & 0.189 & 10 \\
\hline \multirow{3}{*}{$(18: 0)_{2} \mathrm{PC}$} & $\mathrm{L}_{\mathrm{C}^{\prime}}$ & -4 & 0.444 & 0.390 & 0.494 & 0.434 & 116 & 0.193 & 11 \\
\hline & & 4 & 0.441 & 0.388 & 0.491 & 0.432 & 116 & 0.191 & 4 \\
\hline & & 20 & 0.442 & 0.399 & 0.495 & 0.447 & 117 & 0.198 & 4 \\
\hline$(\mathrm{i} 17: 0)_{2} \mathrm{PC}$ & $\mathrm{L}_{\mathrm{C}^{\prime}}$ & $<19$ & 0.455 & 0.378 & 0.500 & 0.416 & 115 & 0.189 & 10 \\
\hline$(\mathrm{i} 20: 0)_{2} \mathrm{PC}$ & $\mathrm{L}_{\mathrm{C}^{\prime}}$ & $<44$ & 0.462 & 0.375 & 0.506 & 0.410 & 114 & 0.190 & 10 \\
\hline \multirow[t]{2}{*}{$(10: 0 / 18: 0) P C$} & $\mathrm{~L}_{\mathrm{C}^{\prime}}$ & -4 & 0.456 & 0.382 & 0.502 & 0.421 & 115 & 0.192 & 11 \\
\hline & & 0 & 0.450 & 0.380 & 0.496 & 0.419 & 115 & 0.189 & 12 \\
\hline \multirow[t]{2}{*}{ (12:0/18:0)PC } & $\mathrm{L}_{\mathrm{C}^{\prime}}$ & -4 & 0.456 & 0.380 & 0.502 & 0.418 & 115 & 0.191 & 11 \\
\hline & & 13 & 0.456 & 0.380 & 0.502 & 0.418 & 115 & 0.191 & 11 \\
\hline \multirow[t]{3}{*}{$(14: 0 / 16: 0) \mathrm{PC}$} & $\mathrm{L}_{\mathrm{C}^{\prime}}$ & -3 & 0.450 & 0.372 & 0.494 & 0.409 & 114 & 0.184 & 13 \\
\hline & & 5 & 0.447 & 0.370 & 0.491 & 0.406 & 114 & 0.182 & 4 \\
\hline & & 15 & 0.447 & 0.371 & 0.491 & 0.408 & 115 & 0.182 & 14 \\
\hline \multirow[t]{2}{*}{$(14: 0 / 18: 0) P C$} & $\mathrm{~L}_{\mathrm{C}^{\prime}}$ & -4 & 0.450 & 0.386 & 0.498 & 0.427 & 115 & 0.192 & 11 \\
\hline & & 4 & 0.434 & 0.386 & 0.485 & 0.431 & 116 & 0.187 & 4 \\
\hline \multirow[t]{2}{*}{$(16: 0 / 14: 0) \mathrm{PC}$} & $\mathrm{L}_{\mathrm{c}^{\prime}}$ & -9 & 0.447 & 0.393 & 0.498 & 0.438 & 116 & 0.196 & 13 \\
\hline & & 3 & 0.440 & 0.384 & 0.489 & 0.427 & 116 & 0.188 & 4 \\
\hline (16:0/18:0)PC & $\mathrm{L}_{\mathrm{C}^{\prime}}$ & -4 & 0.452 & 0.373 & 0.496 & 0.409 & 114 & 0.185 & 11 \\
\hline & & 3 & 0.446 & 0.367 & 0.489 & 0.403 & 114 & 0.180 & 4 \\
\hline & & 36 & 0.451 & 0.379 & 0.497 & 0.418 & 115 & 0.188 & 11 \\
\hline$(18: 0 / 12: 0) \mathrm{PC}$ & $\mathrm{L}_{\mathrm{C}^{\prime}}$ & -4 & 0.453 & 0.376 & 0.498 & 0.413 & 115 & 0.187 & 11 \\
\hline$(18: 0 / 14: 0) \mathrm{PC}$ & $\mathrm{L}_{\mathrm{C}^{\prime}}$ & -4 & 0.454 & 0.376 & 0.499 & 0.413 & 114 & 0.188 & 11 \\
\hline & & 4 & 0.449 & 0.372 & 0.493 & 0.409 & 114 & 0.184 & 4 \\
\hline$(18: 0 / 16: 0) \mathrm{PC}$ & $\mathrm{L}_{\mathrm{C}^{\prime}}$ & -4 & 0.457 & 0.394 & 0.506 & 0.437 & 116 & 0.200 & 11 \\
\hline & & 4 & 0.447 & 0.388 & 0.496 & 0.431 & 116 & 0.193 & 4 \\
\hline & & 23 & 0.447 & 0.388 & 0.496 & 0.431 & 116 & 0.193 & 4 \\
\hline $1,3-(14: 0)_{2} \mathrm{PC}$ & $\mathrm{L}_{\mathrm{C}^{\prime}}$ & 2 & 0.425 & 0.407 & 0.484 & 0.464 & 119 & 0.197 & 4 \\
\hline $1,3-(16: 0)_{2} \mathrm{PC}$ & $\mathrm{L}_{\mathrm{C}^{\prime}}$ & 5 & 0.43 & 0.414 & 0.49 & 0.47 & 119 & 0.20 & 4,15 \\
\hline & & 6 & 0.42 & 0.37 & 0.47 & 0.41 & 116 & 0.17 & 16 \\
\hline 1,3-(18:0/14:0)PC & $\mathrm{L}_{\mathrm{C}^{\prime}}$ & 5 & 0.433 & 0.376 & 0.481 & 0.417 & 116 & 0.181 & 4 \\
\hline 1,3-(18:0/16:0)PC & $\mathrm{L}_{\mathrm{C}^{\prime}}$ & 2 & 0.426 & 0.367 & 0.472 & 0.407 & 116 & 0.173 & 4 \\
\hline$(14: 0)_{4} \mathrm{CL}$ & $\mathrm{L}_{\mathrm{c}^{\prime}}$ & 2 & 0.460 & 0.380 & 0.505 & 0.417 & 114 & 0.192 & 17 \\
\hline$(10: 0)_{2}$ Glc $\alpha$ DG & $\mathrm{L}_{\mathrm{c}}^{\mathrm{a}}$ & 0 & 0.41 & 0.40 & 0.470 & 0.458 & 119 & 0.188 & 18 \\
\hline$(11: 0)_{2}$ Glc $\alpha$ DG & $\mathrm{L}_{\mathrm{c}}^{\mathrm{a}}$ & 0 & 0.41 & 0.40 & 0.470 & 0.458 & 119 & 0.188 & 18 \\
\hline$(12: 0)_{2} \mathrm{Glc} \alpha \mathrm{DG}$ & $\mathrm{L}_{\mathrm{c}}^{\mathrm{a}}$ & 20 & 0.43 & 0.40 & 0.486 & 0.452 & 118 & 0.194 & 18 \\
\hline$(13: 0)_{2}$ Glc $\alpha$ DG & $\mathrm{L}_{\mathrm{c}}^{\mathrm{a}}$ & 20 & 0.42 & 0.40 & 0.478 & 0.455 & 118 & 0.191 & 18 \\
\hline$(14: 0)_{2}$ Glc $\alpha$ DG & $\mathrm{L}_{\mathrm{c}}^{\mathrm{a}}$ & 20 & 0.43 & 0.41 & 0.489 & 0.466 & 118 & 0.201 & 18 \\
\hline$(15: 0)_{2}$ Glc $\alpha$ DG & $\mathrm{L}_{\mathrm{c}}^{\mathrm{a}}$ & 20 & 0.41 & 0.40 & 0.470 & 0.458 & 119 & 0.188 & 18 \\
\hline$(16: 0)_{2}$ Glc $\alpha$ DG & $\mathrm{L}_{\mathrm{c}}^{\mathrm{a}}$ & 20 & 0.41 & 0.40 & 0.470 & 0.458 & 119 & 0.188 & 18 \\
\hline$(17: 0)_{2}$ Glc $\alpha$ DG & $\mathrm{L}_{\mathrm{c}}^{\mathrm{a}}$ & 20 & 0.43 & 0.40 & 0.486 & 0.452 & 118 & 0.194 & 18 \\
\hline$(18: 0)_{2}$ Glc $\alpha$ DG & $\mathrm{L}_{\mathrm{c}}^{\mathrm{a}}$ & 20 & 0.41 & 0.40 & 0.470 & 0.458 & 119 & 0.188 & 18 \\
\hline$(19: 0)_{2}$ Glc $\alpha$ DG & $\mathrm{L}_{\mathrm{c}}^{\mathrm{a}}$ & 20 & 0.43 & 0.40 & 0.486 & 0.452 & 118 & 0.194 & 18 \\
\hline$(20: 0)_{2}$ Glc $\alpha$ DG & $\mathrm{L}_{\mathrm{c}}^{\mathrm{a}}$ & 20 & 0.41 & 0.40 & 0.470 & 0.458 & 119 & 0.188 & 18 \\
\hline$(0-12: 0)_{2}$ Glc $\beta D G$ & $\mathrm{~L}_{\mathrm{c}}^{\mathrm{a}}$ & 20 & 0.444 & 0.374 & 0.490 & 0.412 & 115 & 0.183 & 19 \\
\hline & & 30 & 0.445 & 0.384 & 0.493 & 0.426 & 116 & 0.189 & 20 \\
\hline$(0-14: 0)_{2}$ Glc $\beta D G$ & $\mathrm{~L}_{\mathrm{c}}^{\mathrm{a}}$ & 20 & 0.442 & 0.381 & 0.490 & 0.422 & 116 & 0.187 & 20 \\
\hline & & & 0.444 & 0.371 & 0.489 & 0.408 & 115 & 0.181 & 19 \\
\hline & & & 0.460 & 0.390 & 0.508 & 0.431 & 115 & 0.198 & 21 \\
\hline$(0-16: 0)_{2} \operatorname{Lac} \beta D G$ & $\mathrm{~L}_{\mathrm{c}}^{\mathrm{a}}$ & 20 & 0.45 & 0.38 & 0.496 & 0.419 & 115 & 0.189 & 19 \\
\hline & & & 0.445 & 0.376 & 0.491 & 0.415 & 115 & 0.185 & 22 \\
\hline & & 65 & 0.45 & 0.39 & 0.499 & 0.433 & 116 & 0.195 & 22 \\
\hline$(15: 0)_{2} \mathrm{PC}$ & $m \mathrm{~L}_{\beta^{\prime}}$ & -15 & 0.431 & 0.395 & 0.485 & 0.444 & 117 & 0.192 & 1 \\
\hline$(16: 0)_{2} \mathrm{PC}$ & $m \mathrm{~L}_{\beta^{\prime}}$ & -15 & 0.428 & 0.392 & 0.481 & 0.441 & 117 & 0.189 & 1 \\
\hline$(18: 0)_{2} \mathrm{PC}$ & $m \mathrm{~L}_{\beta^{\prime}}$ & -10 & 0.433 & 0.397 & 0.487 & 0.447 & 117 & 0.193 & 1 \\
\hline$(16: 0)_{2} \mathrm{PEMe}_{2}$ & $m \mathrm{~L}_{\beta^{\prime}}$ & 0 & 0.427 & 0.405 & 0.485 & 0.460 & 118 & 0.196 & 1 \\
\hline$(16: 0)_{2} \mathrm{PG}$ & $m \mathrm{~L}_{\beta^{\prime}}$ & -20 & 0.431 & 0.401 & 0.487 & 0.453 & 118 & 0.195 & 1 \\
\hline$(\mathrm{O}-16: 0)_{2} \mathrm{PA}, \mathrm{pH} 12$ & $m \mathrm{~L}_{\beta^{\prime}}$ & 5 & 0.434 & 0.401 & 0.489 & 0.452 & 118 & 0.196 & 23 \\
\hline$(14: 0)_{2} \mathrm{PC}$ & $\mathrm{L}_{\beta^{\prime}}$ & 4 & 0.417 & 0.407 & 0.478 & 0.466 & 119 & 0.194 & 4 \\
\hline & & 5 & 0.420 & 0.414 & 0.483 & 0.476 & 120 & 0.200 & 24 \\
\hline & & 5 & 0.419 & 0.410 & 0.480 & 0.470 & 119 & 0.197 & 25 \\
\hline & & 10 & 0.425 & 0.409 & 0.485 & 0.467 & 119 & 0.198 & 26 \\
\hline & & & 0.422 & 0.412 & 0.484 & 0.472 & 119 & 0.199 & 1 \\
\hline & & $20^{\mathrm{b}}$ & 0.425 & 0.416 & 0.487 & 0.477 & 119 & 0.203 & 27 \\
\hline$(15: 0)_{2} \mathrm{PC}$ & $\mathrm{L}_{\beta^{\prime}}$ & 10 & 0.421 & 0.408 & 0.481 & 0.466 & 119 & 0.196 & 1 \\
\hline$(16: 0)_{2} \mathrm{PC}$ & $\mathrm{L}_{\beta^{\prime}}$ & $4^{c}$ & 0.420 & 0.400 & 0.478 & 0.455 & 118 & 0.191 & 28 \\
\hline & & 5 & 0.420 & 0.400 & 0.478 & 0.455 & 118 & 0.191 & 23 \\
\hline
\end{tabular}


Table 5 (Continued)

\begin{tabular}{|c|c|c|c|c|c|c|c|c|c|}
\hline Lipid & Phase & $T\left({ }^{\circ} \mathrm{C}\right)$ & $s_{20}(\mathrm{~nm})$ & $s_{11}(\mathrm{~nm})$ & $a_{c h}(\mathrm{~nm})$ & $b_{c h}(\mathrm{~nm})$ & $\gamma_{c h}\left({ }^{\circ}\right)$ & $A_{c h}\left(\mathrm{~nm}^{2}\right)$ & Ref. \\
\hline & & 5 & 0.427 & 0.403 & 0.484 & 0.458 & 118 & 0.195 & 29 \\
\hline & & 7 & 0.425 & 0.407 & 0.484 & 0.464 & 119 & 0.197 & 30 \\
\hline & & 10 & 0.425 & 0.406 & 0.484 & 0.462 & 119 & 0.196 & 8 \\
\hline & & 10 & 0.425 & 0.407 & 0.484 & 0.463 & 119 & 0.197 & 29 \\
\hline & & 14 & 0.418 & 0.407 & 0.479 & 0.466 & 119 & 0.195 & 31 \\
\hline & & 15 & 0.423 & 0.405 & 0.482 & 0.461 & 119 & 0.195 & 3 \\
\hline & & 15 & 0.424 & 0.410 & 0.484 & 0.468 & 119 & 0.198 & 29 \\
\hline & & 19 & 0.424 & 0.414 & 0.486 & 0.474 & 119 & 0.201 & 32 \\
\hline & & 20 & 0.418 & 0.408 & 0.479 & 0.467 & 119 & 0.195 & 33 \\
\hline & & 20 & 0.424 & 0.411 & 0.485 & 0.471 & 119 & 0.199 & 29 \\
\hline & & 20 & 0.422 & 0.409 & 0.482 & 0.468 & 119 & 0.197 & 24 \\
\hline & & 20 & 0.424 & 0.410 & 0.484 & 0.468 & 119 & 0.199 & 34 \\
\hline & & 20 & 0.420 & 0.405 & 0.479 & 0.462 & 119 & 0.194 & 4 \\
\hline & & 20 & 0.420 & 0.407 & 0.480 & 0.465 & 119 & 0.195 & 1 \\
\hline & & 24 & 0.424 & 0.418 & 0.488 & 0.481 & 120 & 0.204 & 32 \\
\hline & & 25 & 0.424 & 0.415 & 0.486 & 0.476 & 119 & 0.202 & 35 \\
\hline & & 25 & 0.424 & 0.413 & 0.486 & 0.473 & 119 & 0.201 & 29 \\
\hline & & 30 & 0.424 & 0.415 & 0.486 & 0.476 & 119 & 0.202 & 29 \\
\hline & & 33 & 0.420 & 0.413 & 0.482 & 0.474 & 119 & 0.199 & 28 \\
\hline & & 33.2 & 0.424 & 0.418 & 0.487 & 0.480 & 120 & 0.204 & 36 \\
\hline$(17: 0)_{2} \mathrm{PC}$ & $\mathrm{L}_{\beta^{\prime}}$ & 19 & 0.423 & 0.406 & 0.482 & 0.463 & 119 & 0.196 & 37 \\
\hline \multirow[t]{11}{*}{$(18: 0)_{2} \mathrm{PC}$} & $\mathrm{L}_{\beta^{\prime}}$ & 19 & 0.429 & 0.406 & 0.487 & 0.461 & 118 & 0.197 & 37 \\
\hline & & 25 & 0.424 & 0.411 & 0.485 & 0.470 & 119 & 0.199 & 1 \\
\hline & & 25 & 0.426 & 0.409 & 0.485 & 0.466 & 119 & 0.198 & 35 \\
\hline & & 25 & 0.426 & 0.408 & 0.486 & 0.465 & 119 & 0.198 & 29 \\
\hline & & 30 & 0.425 & 0.412 & 0.486 & 0.470 & 119 & 0.200 & 29 \\
\hline & & 35 & 0.425 & 0.414 & 0.487 & 0.474 & 119 & 0.201 & 29 \\
\hline & & 40 & 0.425 & 0.416 & 0.487 & 0.477 & 119 & 0.203 & 29 \\
\hline & & 40 & 0.423 & 0.413 & 0.485 & 0.473 & 119 & 0.200 & 4 \\
\hline & & 41 & 0.426 & 0.403 & 0.484 & 0.457 & 118 & 0.195 & 11 \\
\hline & & 45 & 0.426 & 0.417 & 0.488 & 0.478 & 119 & 0.204 & 29 \\
\hline & & 48 & 0.425 & 0.415 & 0.487 & 0.476 & 119 & 0.202 & 38 \\
\hline$(19: 0)_{2} \mathrm{PC}$ & $\mathrm{L}_{\beta^{\prime}}$ & 19 & 0.430 & 0.400 & 0.486 & 0.453 & 118 & 0.194 & 37 \\
\hline \multirow{12}{*}{$(20: 0)_{2} \mathrm{PC}$} & $\mathrm{L}_{\beta^{\prime}}$ & 10 & 0.434 & 0.395 & 0.488 & 0.444 & 117 & 0.193 & 29 \\
\hline & & 15 & 0.434 & 0.398 & 0.488 & 0.447 & 117 & 0.194 & 29 \\
\hline & & 19 & 0.434 & 0.397 & 0.488 & 0.447 & 117 & 0.194 & 37 \\
\hline & & 20 & 0.433 & 0.400 & 0.488 & 0.451 & 118 & 0.195 & 29 \\
\hline & & 25 & 0.431 & 0.403 & 0.487 & 0.456 & 118 & 0.196 & 29 \\
\hline & & 30 & 0.429 & 0.406 & 0.487 & 0.461 & 118 & 0.198 & 29 \\
\hline & & 35 & 0.427 & 0.408 & 0.486 & 0.464 & 119 & 0.198 & 29 \\
\hline & & 40 & 0.426 & 0.411 & 0.486 & 0.468 & 119 & 0.200 & 29 \\
\hline & & 45 & 0.426 & 0.413 & 0.487 & 0.472 & 119 & 0.201 & 29 \\
\hline & & 50 & 0.426 & 0.415 & 0.487 & 0.475 & 119 & 0.202 & 29 \\
\hline & & 55 & 0.426 & 0.417 & 0.488 & 0.478 & 119 & 0.204 & 29 \\
\hline & & 60 & 0.427 & 0.419 & 0.490 & 0.481 & 119 & 0.205 & 29 \\
\hline \multirow[t]{15}{*}{$(22: 0)_{2} \mathrm{PC}$} & $\mathrm{L}_{\beta^{\prime}}$ & 5 & 0.435 & 0.411 & 0.494 & 0.466 & 118 & 0.203 & 39 \\
\hline & & 20 & 0.433 & 0.396 & 0.487 & 0.445 & 117 & 0.193 & 40 \\
\hline & & 23 & 0.433 & 0.411 & 0.492 & 0.467 & 118 & 0.202 & 39 \\
\hline & & 25 & 0.435 & 0.395 & 0.488 & 0.444 & 117 & 0.193 & 29 \\
\hline & & 25 & 0.435 & 0.399 & 0.490 & 0.449 & 117 & 0.195 & 35 \\
\hline & & 30 & 0.433 & 0.401 & 0.489 & 0.453 & 118 & 0.196 & 29 \\
\hline & & 35 & 0.431 & 0.404 & 0.488 & 0.457 & 118 & 0.197 & 29 \\
\hline & & 40 & 0.430 & 0.407 & 0.488 & 0.462 & 118 & 0.198 & 29 \\
\hline & & 45 & 0.428 & 0.409 & 0.487 & 0.466 & 119 & 0.199 & 29 \\
\hline & & 50 & 0.427 & 0.411 & 0.487 & 0.469 & 119 & 0.201 & 29 \\
\hline & & 50 & 0.425 & 0.411 & 0.486 & 0.470 & 119 & 0.200 & 39 \\
\hline & & 55 & 0.427 & 0.414 & 0.488 & 0.474 & 119 & 0.202 & 29 \\
\hline & & 60 & 0.427 & 0.416 & 0.489 & 0.477 & 119 & 0.203 & 29 \\
\hline & & 65 & 0.427 & 0.419 & 0.490 & 0.481 & 119 & 0.206 & 29 \\
\hline & & 70 & 0.429 & 0.422 & 0.492 & 0.484 & 119 & 0.207 & 29 \\
\hline \multirow[t]{13}{*}{$(24: 0)_{2} \mathrm{PC}$} & $\mathrm{L}_{\beta^{\prime}}$ & 25 & 0.437 & 0.394 & 0.490 & 0.441 & 117 & 0.193 & 35 \\
\hline & & 25 & 0.437 & 0.394 & 0.490 & 0.441 & 117 & 0.193 & 29 \\
\hline & & 30 & 0.437 & 0.397 & 0.490 & 0.445 & 117 & 0.194 & 29 \\
\hline & & 35 & 0.435 & 0.399 & 0.490 & 0.448 & 117 & 0.195 & 29 \\
\hline & & 40 & 0.433 & 0.402 & 0.489 & 0.453 & 118 & 0.196 & 29 \\
\hline & & 45 & 0.431 & 0.405 & 0.488 & 0.459 & 118 & 0.198 & 29 \\
\hline & & 50 & 0.430 & 0.409 & 0.488 & 0.464 & 118 & 0.199 & 29 \\
\hline & & 55 & 0.429 & 0.412 & 0.489 & 0.470 & 119 & 0.202 & 29 \\
\hline & & 60 & 0.428 & 0.415 & 0.489 & 0.474 & 119 & 0.203 & 29 \\
\hline & & 65 & 0.428 & 0.418 & 0.490 & 0.479 & 119 & 0.205 & 29 \\
\hline & & 70 & 0.428 & 0.419 & 0.491 & 0.481 & 119 & 0.206 & 29 \\
\hline & & 75 & 0.428 & 0.421 & 0.492 & 0.483 & 119 & 0.207 & 29 \\
\hline & & 80 & 0.430 & 0.423 & 0.493 & 0.485 & 119 & 0.208 & 29 \\
\hline$(\mathrm{i} 17: 0)_{2} \mathrm{PC}$ & $\mathrm{L}_{\beta^{\prime}}$ & $19-28$ & 0.440 & 0.385 & 0.489 & 0.428 & 116 & 0.188 & 10 \\
\hline$(\mathrm{i} 20: 0)_{2} \mathrm{PC}$ & $\mathrm{L}_{\beta^{\prime}}$ & $44-52$ & 0.440 & 0.400 & 0.494 & 0.449 & 117 & 0.198 & 10 \\
\hline (14:0/18:0)PC & $\mathrm{L}_{\beta^{\prime}}$ & 8 & 0.448 & 0.420 & 0.507 & 0.475 & 118 & 0.213 & 11 \\
\hline$(16: 0 / 18: 0) \mathrm{PC}$ & $\mathrm{L}_{\beta^{\prime}}$ & 22 & 0.441 & 0.427 & 0.504 & 0.488 & 119 & 0.215 & 11 \\
\hline
\end{tabular}


Table 5 (Continued)

\begin{tabular}{|c|c|c|c|c|c|c|c|c|c|}
\hline Lipid & Phase & $T\left({ }^{\circ} \mathrm{C}\right)$ & $s_{20}(\mathrm{~nm})$ & $s_{11}(\mathrm{~nm})$ & $a_{c h}(\mathrm{~nm})$ & $b_{c h}(\mathrm{~nm})$ & $\gamma_{c h}\left({ }^{\circ}\right)$ & $A_{c h}\left(\mathrm{~nm}^{2}\right)$ & Ref. \\
\hline$(18: 0 / 2: 0) P C^{d}$ & $\mathrm{~L}_{\beta^{\prime}}$ & -8 & 0.427 & 0.401 & 0.484 & 0.454 & 118 & 0.194 & 41 \\
\hline \multirow[t]{2}{*}{ (18:0/14:0)PC } & $\mathrm{L}_{\beta^{\prime}} \mathrm{e}$ & 7 & 0.425 & 0.406 & 0.484 & 0.462 & 119 & 0.196 & 11 \\
\hline & & 13 & 0.421 & 0.410 & 0.482 & 0.469 & 119 & 0.198 & 42 \\
\hline$(18: 0 / 16: 0) \mathrm{PC}$ & $\mathrm{L}_{\beta^{\prime}}$ & 16 & 0.435 & 0.423 & 0.498 & 0.484 & 119 & 0.211 & 11 \\
\hline$\left(20: 0 / 20: 1 c \Delta^{13}\right) \mathrm{PC}$ & $\mathrm{L}_{\beta^{\prime}}$ & 20 & 0.431 & 0.417 & 0.492 & 0.476 & 119 & 0.205 & 43 \\
\hline (O-12:0/0-20:0)PC & $\mathrm{L}_{\beta^{\prime}}$ & -4 & 0.431 & 0.406 & 0.489 & 0.460 & 118 & 0.198 & 11 \\
\hline (O-16:0/2-Pr16:0)PC & $\mathrm{L}_{\beta^{\prime}}$ & 25 & 0.430 & 0.414 & 0.491 & 0.472 & 119 & 0.203 & 44 \\
\hline$(14: 0)_{2} \mathrm{PG}$ & $\mathrm{L}_{\beta^{\prime}}$ & 8 & 0.420 & 0.405 & 0.479 & 0.462 & 119 & 0.194 & 45 \\
\hline \multirow[t]{8}{*}{$(16: 0)_{2} \mathrm{PG}$} & $\mathrm{L}_{\beta^{\prime}}$ & 3 & 0.428 & 0.405 & 0.486 & 0.460 & 118 & 0.197 & 46 \\
\hline & & 20 & 0.420 & 0.413 & 0.482 & 0.474 & 119 & 0.199 & 46 \\
\hline & $\mathrm{L}_{\beta^{\prime}}$ & 22 & 0.420 & 0.407 & 0.480 & 0.465 & 119 & 0.195 & 47 \\
\hline & $\mathrm{L}_{\beta^{\prime}}$ & 25 & 0.424 & 0.412 & 0.485 & 0.471 & 119 & 0.200 & 1 \\
\hline & $\mathrm{L}_{\beta^{\prime}}$ & 25 & 0.425 & 0.418 & 0.488 & 0.480 & 119 & 0.204 & 47 \\
\hline & & & 0.426 & 0.415 & 0.488 & 0.475 & 119 & 0.202 & 48 \\
\hline & & & 0.417 & 0.410 & 0.479 & 0.471 & 119 & 0.196 & 49 \\
\hline & $\mathrm{L}_{\beta^{\prime}}$ & 38 & 0.425 & 0.420 & 0.489 & 0.483 & 120 & 0.205 & 45 \\
\hline \multirow[t]{2}{*}{$(18: 0)_{2} \mathrm{PG}$} & $\mathrm{L}_{\beta^{\prime}}$ & 2 & 0.433 & 0.408 & 0.491 & 0.463 & 118 & 0.200 & 47 \\
\hline & & 35 & 0.427 & 0.416 & 0.489 & 0.476 & 119 & 0.203 & 47 \\
\hline$(16: 0)_{2}$ PGLys & $\mathrm{L}_{\beta^{\prime}}$ & 15 & 0.427 & 0.413 & 0.488 & 0.472 & 119 & 0.201 & 50 \\
\hline$(\mathrm{O}-16: 0)_{2} \mathrm{PA}, \mathrm{pH} 12$ & $\mathrm{~L}_{\beta^{\prime}}$ & 20 & 0.428 & 0.410 & 0.488 & 0.467 & 119 & 0.200 & 23 \\
\hline $\operatorname{SM}(\mathrm{d} 18: 1 / 24: 0)$ & $\mathrm{L}_{\beta^{\prime}}$ & 22 & 0.418 & 0.399 & 0.476 & 0.454 & 119 & 0.190 & 51 \\
\hline (18:0/0:0)LPC & $\mathrm{L}_{\beta^{\prime}}^{\mathrm{i}}$ & 10 & 0.430 & 0.410 & 0.489 & 0.466 & 118 & 0.201 & 52 \\
\hline
\end{tabular}

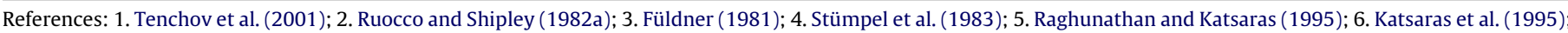

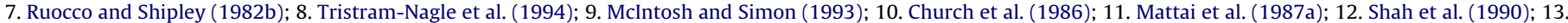

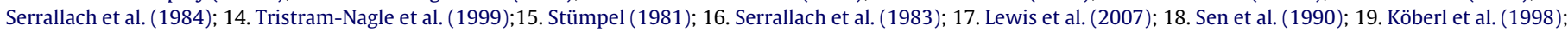

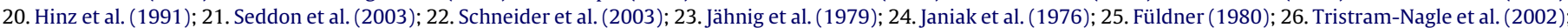

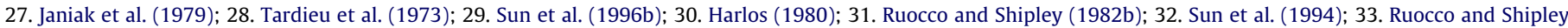

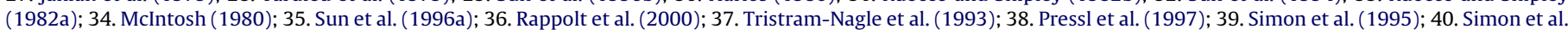

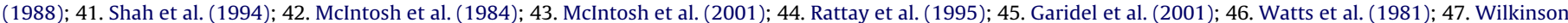
et al. (1987); 48. Pabst et al. (2007); 49. Zweytick et al. (2006); 50. Danner et al. (2008); 51. Maulik and Shipley (1995); 52. Mattai and Shipley (1986).

a Tentative assignments.

b Sample with $16 \mathrm{wt} \%$ water (limiting hydration is $20 \%$ water).

c Sample with 20 wt\% water (limiting hydration is $<25 \%$ water).

d Sample with 80 wt\% water.

e Sample with $30 \mathrm{wt} \%$ water.

and Katsaras (1996), according to the assignments established from aligned samples of $(16: 0)_{2} \mathrm{PC}$ (Katsaras et al., 1995). Other $\mathrm{L}_{\mathrm{c}^{\prime}}$ phases from the same reference are indexed analogously. Examination of the wide-angle diffraction profiles for the 1,3-diacyl phosphatidylcholines (Stümpel et al., 1983; Stümpel, 1981) indicates a more complicated behaviour than for the $\mathrm{L}_{\mathrm{c}^{\prime}}$ phase of 1,2-diacyl phosphatidylcholines. Therefore, the assignments for the 1,3-isomers must be considered as being tentative, although a reasonably consistent agreement with the molecular sublattice (see Appendix A) is achieved (Raghunathan and Katsaras, 1996).

Assignment of the chain reflections for the $\mathrm{L}_{\mathrm{c}^{\prime}}$ subgel phase of mixed-chain phosphatidylcholines from Mattai et al. (1987a) are made according to Ruocco and Shipley (1982a) for (16:0) ${ }_{2} \mathrm{PC}$, which is also in accord with the assignment of Katsaras et al. (1995).

For $(13: 0)_{2} \mathrm{Glc} \alpha \mathrm{DG}$, the relative intensities of the wide-angle reflections for the crystalline state support an assignment to a distorted hexagonal type of chain sublattice ( $2 \mathrm{nn})$, as is given in Table 5. From the similarity in chain short spacings, this assignment is assumed for the remainder of the homologous series but must be considered as being tentative. It yields relatively small areas per chain, consistent with a crystalline phase, but so also would the reverse assignment corresponding to the orthogonal chain packing mode. The gradient in long spacing with chain length suggests that the chains are tilted, as in $\mathrm{L}_{\mathrm{c}}{ }^{\prime}$ subgel phases of phosphatidylcholines (Sen et al., 1990). However, the short spacings for the whole $(n: 0)_{2}$ Glc $\alpha$ DG series, especially the higher homologues, are atypical when compared with those for phases with well-established distorted hexagonal chain packing (see Tables 2 and 5).

The short spacings for the crystalline phases of dialkyl glucosyl glycerols, $(\mathrm{O}-n: 0)_{2} \mathrm{Glc} \beta \mathrm{DG}$, are comparable to those of the $\mathrm{L}_{\mathrm{c}^{\prime}}$ phases of phosphatidylcholines (see Tables 2 and 5). The relative intensities of the wide-angle reflections for $(0-14: 0)_{2}$ Glc $\beta D G$ could be consistent with this assignment (Seddon et al., 2003; Köberl et al., 1998). A complication is that a third reflection at $0.356 \mathrm{~nm}$ is seen for (0-14:0) ${ }_{2}$ Glc $\beta$ DG by Hinz et al.(1991), but neither by Köberl et al. (1998) nor by Seddon et al. (2003). (For an oblique sublattice assignment including this extra reflection, see Table 3.) Köberl et al. (1998) have suggested an orthorhombic-triclinic hybrid subcell for the (O- $n: 0)_{2}$ Glc $\beta D G$ series and also for the crystalline lamellar phase of (0-16:0) 2 Lac $\beta D G$. Schneider et al. (2003) propose triclinic packing for the latter, although only two reflections are found in the chain region, and the spacings are again comparable to those of the $\mathrm{L}_{\mathrm{c}^{\prime}}$ phase. Again, therefore, the assignments in Table 5 must be considered as being only tentative, and the existence of an $\mathrm{L}_{\mathrm{c}^{\prime}}$-like phase in a glycolipid system is not well established.

Assignment to the $m \mathrm{~L}_{\beta^{\prime}}$ phase that is shown for (16:0) $)_{2} \mathrm{PEMe}_{2}$ in Table 5 is considered to be tentative (Tenchov et al., 2001). On balance, relative intensities of the wide-angle reflections for $(16: 0)_{2} \mathrm{PEMe}_{2}$ support this assignment.

For the propyl $\alpha$-branched lipid (O-16:0/2-Pr16:0)PC, the indexing in the original publication is revised to correspond with the relative intensities of the wide-angle reflections.

For phosphatidic acid (0-16:0) 2 PA in the doubly charged state at high $\mathrm{pH}$, the assignment of the (11) and (20) reflections in the $\mathrm{L}_{\beta^{\prime}}$ phase is reversed from that in the original publication. This reassignment is made on the basis of relative integrated intensities and similarity with wide-angle reflections found for the $\mathrm{L}_{\beta^{\prime}}$ phase of phosphatidylcholines. See also Tenchov et al. (2001).

Lysophosphatidylcholine (18:0/0:0)LPC forms an interdigitated lamellar gel phase with tilted chains on prolonged incubation at low temperature (Mattai and Shipley, 1986). The chain reflections are assigned as in Ruocco and Shipley (1982a). 
Table 6

Wide-angle reflections and subcell dimensions for $\mathrm{L}_{\beta}, \mathrm{L}_{\beta}^{\mathrm{i}}, \mathrm{L}_{\beta}^{\mathrm{mi}}$ and $\mathrm{P}_{\beta^{\prime}}$ phases with hexagonal chain packing.

\begin{tabular}{|c|c|c|c|c|c|c|}
\hline Lipid & Phase & $T\left({ }^{\circ} \mathrm{C}\right)$ & $s(\mathrm{~nm})$ & $a_{c h}(\mathrm{~nm})$ & $A_{c h}\left(\mathrm{~nm}^{2}\right)$ & Ref. \\
\hline \multirow[t]{2}{*}{$(14: 0)_{2} \mathrm{PC}$} & $\mathrm{P}_{\beta^{\prime}}$ & 16 & 0.418 & 0.483 & 0.202 & 1 \\
\hline & & 18 & 0.417 & 0.482 & 0.201 & 2 \\
\hline \multirow[t]{6}{*}{$(16: 0)_{2} \mathrm{PC}$} & $\mathrm{P}_{\beta^{\prime}}$ & 34 & 0.418 & 0.483 & 0.202 & 3 \\
\hline & & 34 & 0.418 & 0.483 & 0.202 & 2 \\
\hline & & 36 & 0.421 & 0.486 & 0.205 & 4 \\
\hline & & 38 & 0.419 & 0.484 & 0.203 & 5 \\
\hline & & 39.6 & 0.425 & 0.491 & 0.209 & 6 \\
\hline & & $34-41$ & 0.420 & 0.485 & 0.204 & 7 \\
\hline \multirow{2}{*}{$(18: 0)_{2} \mathrm{PC}$} & $\mathrm{P}_{\beta^{\prime}}$ & 50 & 0.418 & 0.483 & 0.202 & 2 \\
\hline & & 50 & 0.418 & 0.483 & 0.202 & 8 \\
\hline$(\mathrm{O}-16: 0)_{2} \mathrm{PC}$ & $\mathrm{P}_{\beta^{\prime}}$ & $32.5-43.4$ & 0.420 & 0.485 & 0.204 & 9 \\
\hline$(12: 0 / 18: 0) \mathrm{PC}$ & $\mathrm{P}_{\beta^{\prime}}$ & 13 & 0.428 & 0.494 & 0.212 & 8 \\
\hline \multirow[t]{3}{*}{$(14: 0 / 16: 0) \mathrm{PC}$} & $\mathrm{P}_{\beta^{\prime}}$ & 31 & 0.42 & 0.485 & 0.204 & 10 \\
\hline & & 32 & 0.418 & 0.483 & 0.202 & 2 \\
\hline & & 33 & 0.419 & 0.484 & 0.203 & 11 \\
\hline \multirow[t]{2}{*}{$(14: 0 / 18: 0) \mathrm{PC}$} & $\mathrm{P}_{\beta^{\prime}}$ & 28 & 0.421 & 0.486 & 0.205 & 8 \\
\hline & & 30 & 0.421 & 0.486 & 0.205 & 8 \\
\hline \multirow[t]{2}{*}{$(16: 0 / 14: 0) \mathrm{PC}$} & $\mathrm{P}_{\beta^{\prime}}$ & 18 & 0.42 & 0.485 & 0.204 & 10 \\
\hline & & 18 & 0.415 & 0.479 & 0.199 & 2 \\
\hline \multirow[t]{2}{*}{ (16:0/18:0)PC } & $\mathrm{P}_{\beta^{\prime}}$ & 37 & 0.422 & 0.487 & 0.206 & 8 \\
\hline & & 42 & 0.426 & 0.492 & 0.210 & 8 \\
\hline \multirow[t]{3}{*}{$(18: 0 / 14: 0) \mathrm{PC}$} & $\mathrm{P}_{\beta^{\prime}}$ & 20 & 0.419 & 0.484 & 0.203 & 8 \\
\hline & & 24 & 0.421 & 0.486 & 0.205 & 8 \\
\hline & & 30 & 0.416 & 0.480 & 0.200 & 2 \\
\hline$(18: 0 / 16: 0) \mathrm{PC}$ & $\mathrm{P}_{\beta^{\prime}}$ & 30 & 0.429 & 0.495 & 0.213 & 8 \\
\hline & & 35 & 0.428 & 0.494 & 0.212 & 8 \\
\hline & & 38 & 0.429 & 0.495 & 0.213 & 8 \\
\hline$(16: 0)_{2} \mathrm{PG}$ & $P_{\beta^{\prime}}$ & 36 & 0.412 & 0.476 & 0.196 & 12 \\
\hline & & 39 & 0.415 & 0.479 & 0.199 & 12 \\
\hline$(18: 0)_{2} \mathrm{PG}$ & $\mathrm{P}_{\beta^{\prime}}$ & 50 & 0.422 & 0.487 & 0.206 & 13 \\
\hline$(16: 0)_{2}$ PGLys & $\mathrm{P}_{\beta^{\prime}}$ & 35 & 0.422 & 0.487 & 0.206 & 14 \\
\hline & & 50 & 0.427 & 0.493 & 0.211 & 14 \\
\hline (12:0/20:0)PC & $\mathrm{L}_{\beta}$ & 20 & 0.420 & 0.485 & 0.204 & 15 \\
\hline (14:0/18:0)PC & $\mathrm{L}_{\beta}$ & 31 & 0.415 & 0.479 & 0.199 & 2 \\
\hline$(15: 0 / 17: 0) \mathrm{PC}$ & $\mathrm{L}_{\beta}$ & 20 & 0.420 & 0.485 & 0.204 & 15 \\
\hline (16:0/18:0)PC & $\mathrm{L}_{\beta}$ & 46 & 0.418 & 0.483 & 0.202 & 2 \\
\hline (17:0/15:0)PC & $\mathrm{L}_{\beta}$ & 20 & 0.420 & 0.485 & 0.204 & 15 \\
\hline$(18: 0 / 2: 0) \mathrm{PC}^{\mathrm{a}}$ & $\mathrm{L}_{\beta}$ & 14 & 0.413 & 0.477 & 0.197 & 16 \\
\hline$(18: 0 / 16: 0) P C$ & $\mathrm{~L}_{\beta}$ & 40 & 0.416 & 0.480 & 0.200 & 2 \\
\hline$\left(20: 0 / 20: 1 c \Delta^{5}\right) P C$ & $\mathrm{~L}_{\beta}$ & 20 & 0.421 & 0.486 & 0.205 & 17 \\
\hline$\left(20: 0 / 20: 1 c \Delta^{8}\right) \mathrm{PC}$ & $\mathrm{L}_{\beta}$ & 20 & 0.421 & 0.486 & 0.205 & 17 \\
\hline (O-16:0/2-Me16:0)PC & $\mathrm{L}_{\beta}$ & 25 & 0.42 & 0.485 & 0.204 & 18 \\
\hline 1,3-(18:0/14:0)PC & $\mathrm{L}_{\beta}$ & 20 & 0.413 & 0.477 & 0.197 & 2 \\
\hline 1,3-(18:0/16:0)PC & $\mathrm{L}_{\beta}$ & 35 & 0.408 & 0.471 & 0.192 & 2 \\
\hline$(12: 0)_{2} \mathrm{PE}$ & $\mathrm{L}_{\beta}$ & $20 \pm 2$ & 0.421 & 0.486 & 0.205 & 19 \\
\hline & & 26 & 0.421 & 0.486 & 0.205 & 20 \\
\hline & & 30 & 0.425 & 0.491 & 0.209 & 20 \\
\hline$(14: 0)_{2} \mathrm{PE}$ & $\mathrm{L}_{\beta}$ & 20 & 0.418 & 0.483 & 0.202 & 21 \\
\hline & & 43 & 0.421 & 0.486 & 0.205 & 22 \\
\hline$(16: 0)_{2} \mathrm{PE}$ & $\mathrm{L}_{\beta}$ & 15 & 0.413 & 0.477 & 0.197 & 21 \\
\hline & & 20 & 0.415 & 0.479 & 0.199 & 23 \\
\hline & & 25 & 0.408 & 0.471 & 0.192 & 12 \\
\hline & & 45 & 0.415 & 0.479 & 0.199 & 12 \\
\hline$(18: 0)_{2} \mathrm{PE}$ & $\mathrm{L}_{\beta}$ & 20 & 0.412 & 0.476 & 0.196 & 21 \\
\hline & & 20 & 0.411 & 0.475 & 0.195 & 24 \\
\hline & & 40 & 0.415 & 0.479 & 0.199 & 24 \\
\hline & & 60 & 0.424 & 0.490 & 0.208 & 24 \\
\hline & & 65 & 0.424 & 0.490 & 0.208 & 21 \\
\hline$(20: 0)_{2} \mathrm{PE}$ & $\mathrm{L}_{\beta}$ & 75 & 0.422 & 0.487 & 0.206 & 25 \\
\hline$\left(18: 1 \mathrm{t} \Delta^{9}\right)_{2} \mathrm{PE}$ & $\mathrm{L}_{\beta}$ & -10 & 0.415 & 0.479 & 0.199 & 21 \\
\hline & & 20 & 0.424 & 0.490 & 0.208 & 21 \\
\hline$(\mathrm{O}-12: 0)_{2} \mathrm{PE}$ & $\mathrm{L}_{\beta}$ & 29 & 0.422 & 0.487 & 0.206 & 25 \\
\hline$(\mathrm{O}-14: 0)_{2} \mathrm{PE}$ & $\mathrm{L}_{\beta}$ & 20 & 0.413 & 0.477 & 0.197 & 26 \\
\hline$(\mathrm{O}-16: 0)_{2} \mathrm{PE}$ & $\mathrm{L}_{\beta}$ & 13 & 0.413 & 0.477 & 0.197 & 27 \\
\hline & & 20 & 0.414 & 0.478 & 0.198 & 27 \\
\hline & & 21 & 0.405 & 0.468 & 0.189 & 28 \\
\hline & & 22 & 0.418 & 0.483 & 0.202 & 29 \\
\hline & & 60 & 0.422 & 0.487 & 0.206 & 30 \\
\hline & & 60 & 0.427 & 0.493 & 0.211 & 27 \\
\hline$\left(16: 0 / 18: 1 c \Delta^{9}\right) \mathrm{PE}$ & $\mathrm{L}_{\beta}$ & $<24.7$ & 0.430 & 0.497 & 0.214 & 31 \\
\hline$\left(18: 0 / 18: 1 c \Delta^{9}\right) \mathrm{PE}$ & $\mathrm{L}_{\beta}$ & 20 & 0.427 & 0.493 & 0.211 & 32 \\
\hline & & 25 & 0.429 & 0.495 & 0.213 & 32 \\
\hline & & 30 & 0.431 & 0.498 & 0.214 & 32 \\
\hline$(14: 0)_{2}$ PEMe & $\mathrm{L}_{\beta}$ & 37 & 0.422 & 0.487 & 0.206 & 22 \\
\hline$(14: 0)_{2}$ PEMe $_{2}$ & $\mathrm{~L}_{\beta}$ & 27 & 0.421 & 0.486 & 0.205 & 22 \\
\hline
\end{tabular}


Table 6 (Continued)

\begin{tabular}{|c|c|c|c|c|c|c|}
\hline Lipid & Phase & $T\left({ }^{\circ} \mathrm{C}\right)$ & $s(\mathrm{~nm})$ & $a_{c h}(\mathrm{~nm})$ & $A_{c h}\left(\mathrm{~nm}^{2}\right)$ & Ref. \\
\hline \multirow{2}{*}{$(16: 0)_{2} \mathrm{PEMe}_{2}$} & $\mathrm{~L}_{\beta}$ & 20 & 0.418 & 0.483 & 0.202 & 21 \\
\hline & & 40 & 0.420 & 0.485 & 0.204 & 21 \\
\hline$(16: 0)_{2} \mathrm{PG}, \mathrm{pH} 1.5$ & $\mathrm{~L}_{\beta}$ & 20 & 0.412 & 0.476 & 0.196 & 33 \\
\hline \multirow[t]{2}{*}{$(16: 0)_{2} \mathrm{PG}, \mathrm{pH} 1$} & $\mathrm{~L}_{\beta}$ & 20 & 0.411 & 0.475 & 0.195 & 21 \\
\hline & & 50 & 0.420 & 0.485 & 0.204 & 21 \\
\hline$(\mathrm{O}-14: 0)_{2} \mathrm{PG}, 1 \mathrm{M} \mathrm{CaCl}_{2}$ & $\mathrm{~L}_{\beta}$ & 20 & 0.413 & 0.477 & 0.197 & 34 \\
\hline$\left(16: 0 / 18: 1 c \Delta^{9}\right) P G$ & $\mathrm{~L}_{\beta}$ & $<-5.3$ & 0.426 & 0.492 & 0.210 & 31 \\
\hline$(12: 0)_{2} \mathrm{PS}_{\mathrm{NH}} \mathrm{NH}_{4}$ & $\mathrm{~L}_{\beta}$ & 10 & 0.420 & 0.485 & 0.204 & 35 \\
\hline$(12: 0)_{2}$ PS.Mg & $\mathrm{L}_{\beta}$ & & 0.420 & 0.485 & 0.204 & 36 \\
\hline \multirow[t]{2}{*}{$(14: 0)_{2} \mathrm{PS}_{\mathrm{N}} \mathrm{NH}_{4}$} & $\mathrm{~L}_{\beta}$ & 12 & 0.420 & 0.485 & 0.204 & 35 \\
\hline & & 20 & 0.420 & 0.485 & 0.204 & 35 \\
\hline$(14: 0)_{2} \mathrm{PS} . \mathrm{Na}$ & $\mathrm{L}_{\beta}$ & 20 & 0.418 & 0.483 & 0.202 & 37 \\
\hline$(16: 0)_{2}$ PS.NH $_{4}$ & $\mathrm{~L}_{\beta}$ & 12 & 0.420 & 0.485 & 0.204 & 35 \\
\hline$(16: 0)_{2}$ PS.Na & $\mathrm{L}_{\beta}$ & 38 & 0.419 & 0.484 & 0.203 & 38 \\
\hline$(16: 0)_{2} \mathrm{PS} . \mathrm{Sr}$ & $\mathrm{L}_{\beta}$ & & 0.420 & 0.485 & 0.204 & 36 \\
\hline$(16: 0)_{2} \mathrm{PS} . \mathrm{Ba}$ & $\mathrm{L}_{\beta}$ & & 0.420 & 0.485 & 0.204 & 36 \\
\hline$(18: 0)_{2} \mathrm{PS} \mathrm{NH}_{4}$ & $\mathrm{~L}_{\beta}$ & 20 & 0.420 & 0.485 & 0.204 & 35 \\
\hline$(18: 0)_{2}$ PS.Mg & $\mathrm{L}_{\beta}$ & & 0.420 & 0.485 & 0.204 & 36 \\
\hline \multirow{2}{*}{$(\mathrm{O}-16: 0)_{2}$ PS.Li } & $\mathrm{L}_{\beta}$ & 26 & 0.405 & 0.468 & 0.189 & 39 \\
\hline & & 85 & 0.430 & 0.497 & 0.214 & 39 \\
\hline$(16: 0)_{2}$ PSMe & $\mathrm{L}_{\beta}$ & 22 & 0.421 & 0.486 & 0.205 & 40 \\
\hline$(16: 0)_{2} \mathrm{PA}$ & $\mathrm{L}_{\beta}$ & 40 & 0.419 & 0.484 & 0.203 & 41 \\
\hline$(0-14: 0)_{2} \mathrm{PA}$ & $\mathrm{L}_{\beta}$ & 20 & 0.411 & 0.475 & 0.195 & 42 \\
\hline \multirow[t]{3}{*}{$(0-16: 0)_{2} \mathrm{PA}$} & $\mathrm{L}_{\beta}$ & 20 & 0.412 & 0.476 & 0.196 & 43 \\
\hline & & 40 & 0.417 & 0.482 & 0.201 & 43 \\
\hline & & 60 & 0.425 & 0.491 & 0.209 & 43 \\
\hline \multirow{2}{*}{$(\mathrm{O}-16: 0)_{2} \mathrm{PA}, \mathrm{pH} 12$} & $\mathrm{~L}_{\beta}$ & 40 & 0.427 & 0.493 & 0.211 & 43 \\
\hline & $\mathrm{L}_{\beta}$ & 50 & 0.428 & 0.494 & 0.212 & 43 \\
\hline \multirow[t]{3}{*}{$(14: 0)_{2}$ PAMe.Na } & $\mathrm{L}_{\beta}$ & 12 & 0.412 & 0.476 & 0.196 & 44 \\
\hline & & 22 & 0.414 & 0.478 & 0.198 & 44 \\
\hline & & 31 & 0.417 & 0.482 & 0.201 & 44 \\
\hline$(14: 0)_{2}$ PAMe.Ca $1: 1$ & $\mathrm{~L}_{\beta}$ & 3 & 0.408 & 0.471 & 0.192 & 44 \\
\hline & & 22 & 0.413 & 0.477 & 0.197 & 44 \\
\hline & & 60 & 0.428 & 0.494 & 0.212 & 44 \\
\hline$(14: 0)_{2}$ PAMe, pH 3 & $\mathrm{~L}_{\beta}$ & 3 & 0.409 & 0.472 & 0.193 & 44 \\
\hline$(14: 0)_{4} \mathrm{CL}$ & $\mathrm{L}_{\beta}$ & 35 & 0.427 & 0.493 & 0.211 & 45 \\
\hline$(14: 0)_{4} \mathrm{PA}$ & $\mathrm{L}_{\beta}$ & 54 & 0.420 & 0.485 & 0.204 & 46 \\
\hline $\operatorname{SM}(d 18: 1 / 16: 0)$ & $\mathrm{L}_{\beta}$ & 12 & 0.416 & 0.480 & 0.200 & 47 \\
\hline & $\mathrm{L}_{\beta}$ & 29 & 0.420 & 0.485 & 0.204 & 47 \\
\hline SM(d18:1/18:0) & $\mathrm{L}_{\beta}$ & 12 & 0.417 & 0.482 & 0.201 & 48 \\
\hline & $\mathrm{L}_{\beta}$ & 40 & 0.426 & 0.492 & 0.210 & 48 \\
\hline $\operatorname{SM}(d 18: 1 / 24: 0)$ & $\mathrm{L}_{\beta}$ & 20 & 0.415 & 0.479 & 0.199 & 49 \\
\hline & $\mathrm{L}_{\beta}$ & 40 & 0.422 & 0.487 & 0.206 & 50 \\
\hline$(13: 0)_{2}$ Glc $\alpha$ DG & $\mathrm{L}_{\beta}$ & & 0.42 & 0.485 & 0.204 & 51 \\
\hline$(14: 0)_{2}$ Glc $\alpha$ DG & $\mathrm{L}_{\beta}$ & & 0.42 & 0.485 & 0.204 & 51 \\
\hline$(15: 0)_{2}$ Glc $\alpha$ DG & $\mathrm{L}_{\beta}$ & & 0.42 & 0.485 & 0.204 & 51 \\
\hline$(16: 0)_{2}$ Glc $\alpha$ DG & $\mathrm{L}_{\beta}$ & & 0.42 & 0.485 & 0.204 & 51 \\
\hline$(17: 0)_{2}$ Glc $\alpha$ DG & $\mathrm{L}_{\beta}$ & & 0.42 & 0.485 & 0.204 & 51 \\
\hline$(18: 0)_{2} \mathrm{Glc} \alpha \mathrm{DG}$ & $\mathrm{L}_{\beta}$ & & 0.42 & 0.485 & 0.204 & 51 \\
\hline$(19: 0)_{2}$ Glc $\alpha$ DG & $\mathrm{L}_{\beta}$ & & 0.42 & 0.485 & 0.204 & 51 \\
\hline$(20: 0)_{2}$ Glc $\alpha$ DG & $\mathrm{L}_{\beta}$ & & 0.42 & 0.485 & 0.204 & 51 \\
\hline$(0-10: 0)_{2}$ Glc $\beta D G$ & $\mathrm{~L}_{\beta}$ & 20 & 0.420 & 0.485 & 0.204 & 52 \\
\hline$(0-12: 0)_{2}$ Glc $\beta D G$ & $\mathrm{~L}_{\beta}$ & 20 & 0.423 & 0.488 & 0.207 & 52 \\
\hline & & 30 & 0.428 & 0.494 & 0.212 & 53 \\
\hline$(0-14: 0)_{2}$ Glc $\beta D G$ & $\mathrm{~L}_{\beta}$ & 20 & 0.414 & 0.478 & 0.198 & 52 \\
\hline & & & 0.415 & 0.479 & 0.199 & 54 \\
\hline & & & 0.419 & 0.484 & 0.203 & 53 \\
\hline$(0-16: 0)_{2}$ Glc $\beta D G$ & $\mathrm{~L}_{\beta}$ & 20 & 0.413 & 0.477 & 0.197 & 52 \\
\hline$(0-18: 0)_{2}$ Glc $\beta D G$ & $\mathrm{~L}_{\beta}$ & 20 & 0.421 & 0.486 & 0.205 & 52 \\
\hline & & 30 & 0.407 & 0.470 & 0.191 & 53 \\
\hline & & 60 & 0.419 & 0.484 & 0.203 & 53 \\
\hline & & 60 & 0.417 & 0.482 & 0.201 & 53 \\
\hline$(0-14: 0)_{2}$ Gal $\beta D G$ & $\mathrm{~L}_{\beta}$ & 20 & 0.419 & 0.484 & 0.203 & 55 \\
\hline$(0-16: 0)_{2}$ Gal $\beta D G$ & $\mathrm{~L}_{\beta}$ & 20 & 0.410 & 0.473 & 0.194 & 52 \\
\hline$(0-18: 0)_{2}$ Gal $\beta D G$ & $\mathrm{~L}_{\beta}$ & 20 & 0.414 & 0.478 & 0.198 & 53 \\
\hline $2,3-(\mathrm{O}-14: 0)_{2} \mathrm{Gal} \beta \mathrm{DG}$ & $\mathrm{L}_{\beta}$ & 50 & 0.418 & 0.483 & 0.202 & 55 \\
\hline & & & 0.420 & 0.485 & 0.204 & 56 \\
\hline rac- $(0-14: 0)_{2}$ Gal $\beta D G$ & $\mathrm{~L}_{\beta}$ & 20 & 0.415 & 0.479 & 0.199 & 57 \\
\hline & & & 0.420 & 0.485 & 0.204 & 56 \\
\hline rac- $(0-15: 0)_{2}$ Gal $\beta D G$ & $\mathrm{~L}_{\beta}$ & 20 & 0.414 & 0.478 & 0.198 & 57 \\
\hline rac- $(0-16: 0)_{2}$ Gal $\beta D G$ & $\mathrm{~L}_{\beta}$ & 15 & 0.405 & 0.468 & 0.189 & 57 \\
\hline rac- $(\mathrm{O}-18: 0)_{2} \mathrm{Gal} \beta \mathrm{DG}$ & $\mathrm{L}_{\beta}$ & 55 & 0.410 & 0.473 & 0.194 & 57 \\
\hline$(0-16: 0)_{2} \mathrm{Man} \beta \mathrm{DG}$ & $\mathrm{L}_{\beta}$ & 30 & 0.408 & 0.471 & 0.192 & 53 \\
\hline & & 50 & 0.415 & 0.479 & 0.199 & 53 \\
\hline$(0-14: 0)_{2}$ Mal $\beta D G$ & $\mathrm{~L}_{\beta}$ & 20 & 0.410 & 0.473 & 0.194 & 53 \\
\hline & & 35 & 0.415 & 0.479 & 0.199 & 53 \\
\hline$(0-16: 0)_{2}$ Mal $\beta D G$ & $\mathrm{~L}_{\beta}$ & 20 & 0.407 & 0.470 & 0.191 & 53 \\
\hline
\end{tabular}


Table 6 (Continued)

\begin{tabular}{|c|c|c|c|c|c|c|}
\hline Lipid & Phase & $T\left({ }^{\circ} \mathrm{C}\right)$ & $s(\mathrm{~nm})$ & $a_{c h}(\mathrm{~nm})$ & $A_{c h}\left(\mathrm{~nm}^{2}\right)$ & Ref. \\
\hline & & 50 & 0.415 & 0.479 & 0.199 & 53 \\
\hline \multirow[t]{2}{*}{$(0-18: 0)_{2} \mathrm{Mtr} \beta D G$} & $\mathrm{~L}_{\beta}$ & 20 & 0.415 & 0.479 & 0.199 & 53 \\
\hline & & 50 & 0.415 & 0.479 & 0.199 & 53 \\
\hline \multirow{2}{*}{$(0-16: 0)_{2} \operatorname{Lac} \beta_{2} D G$} & $\mathrm{~L}_{\beta}$ & 20 & 0.417 & 0.482 & 0.201 & 58 \\
\hline & & 45 & 0.420 & 0.485 & 0.204 & 58 \\
\hline \multirow[t]{3}{*}{$(\mathrm{O}-18: 0)_{2}$ GlcUAßDG, pH 1.6} & $\mathrm{~L}_{\beta}$ & 20 & 0.406 & 0.469 & 0.190 & 59 \\
\hline & & 40 & 0.409 & 0.472 & 0.193 & 59 \\
\hline & & 60 & 0.415 & 0.479 & 0.199 & 59 \\
\hline \multirow[t]{3}{*}{$(\mathrm{O}-18: 0)_{2}$ GlcUAßDG, pH 10} & $\mathrm{~L}_{\beta}$ & 20 & 0.413 & 0.477 & 0.197 & 59 \\
\hline & & 40 & 0.412 & 0.476 & 0.196 & 59 \\
\hline & & 60 & 0.416 & 0.480 & 0.200 & 59 \\
\hline \multirow[t]{3}{*}{$(\mathrm{O}-16: 0)_{2} \mathrm{PC}$} & $\mathrm{L}_{\beta}^{\mathrm{i}}$ & 20 & 0.410 & 0.473 & 0.194 & 8 \\
\hline & & & 0.409 & 0.472 & 0.193 & 60 \\
\hline & & 22 & 0.408 & 0.471 & 0.192 & 61 \\
\hline$(0-18: 0 / 0-1: 0) P C$ & $\mathrm{~L}_{\beta}^{\mathrm{i}}$ & 0 & 0.430 & 0.497 & 0.214 & 62 \\
\hline (O-16:0/16:0)PC & $\mathrm{L}_{\beta}^{\mathrm{i}}$ & 20 & 0.400 & 0.462 & 0.185 & 63 \\
\hline (O-16:0/2-Bu16:0)PC & $\mathrm{L}_{\beta, \mathrm{i}}$ & 25 & 0.414 & 0.478 & 0.198 & 64 \\
\hline (3-Me16:0/0-16:0)PC & $\mathrm{L}_{\beta, \mathrm{i}}$ & 10 & 0.415 & 0.479 & 0.199 & 65 \\
\hline \multirow[t]{2}{*}{$1,3-(16: 0)_{2} \mathrm{PC}$} & $\mathrm{L}_{\beta}^{\mathrm{i}}$ & 32 & 0.415 & 0.479 & 0.199 & 66 \\
\hline & & 35 & 0.412 & 0.476 & 0.196 & 2 \\
\hline$(2-\mathrm{Pe} 16: 0 / 0-16: 0) \mathrm{PE}$ & $\mathrm{L}_{\beta, \mathrm{I}}$ & 15 & 0.412 & 0.475 & 0.196 & 67 \\
\hline$(2-T t d 16: 0 / 0-16: 0) P E$ & $\mathrm{~L}_{\beta}^{*}$ & 33 & 0.427 & 0.493 & 0.211 & 67 \\
\hline$(16: 0)_{2} \mathrm{PG}$ & $\mathrm{L}_{\beta}^{\mathrm{i}}$ & 22 & 0.410 & 0.473 & 0.194 & 68 \\
\hline \multirow[t]{2}{*}{$(16: 0)_{2}$ PGLys } & $\mathrm{L}_{\beta}^{\mathrm{i}}$ & 15 & 0.413 & 0.477 & 0.197 & 14 \\
\hline & & 35 & 0.416 & 0.480 & 0.200 & 14 \\
\hline$(8: 0 / 18: 0) \mathrm{PC}$ & $\mathrm{L}_{\beta}^{\mathrm{mi}}$ & 0 & 0.410 & 0.473 & 0.194 & 69 \\
\hline \multirow[t]{2}{*}{$(10: 0 / 18: 0) P C$} & $\mathrm{~L}_{\beta}^{\mathrm{mi}}$ & 0 & 0.410 & 0.473 & 0.194 & 69 \\
\hline & & 5 & 0.423 & 0.488 & 0.207 & 8 \\
\hline \multirow[t]{4}{*}{$(18: 0 / 10: 0) P C$} & $\mathrm{~L}_{\beta}^{\mathrm{mi}}$ & -4 & 0.411 & 0.475 & 0.195 & 8 \\
\hline & & 5 & 0.411 & 0.475 & 0.195 & 8 \\
\hline & & 10 & 0.42 & 0.485 & 0.204 & 70 \\
\hline & & 13 & 0.411 & 0.475 & 0.195 & 71 \\
\hline \multirow[t]{2}{*}{$(18: 0 / 12: 0) \mathrm{PC}$} & $\mathrm{L}_{\beta}^{\mathrm{mi}}$ & 8 & 0.411 & 0.475 & 0.195 & 8 \\
\hline & & 10 & 0.42 & 0.485 & 0.204 & 70 \\
\hline (20:0/10:0)PC & $\mathrm{L}_{\beta}^{\mathrm{mi}}$ & 20 & 0.410 & 0.473 & 0.194 & 72 \\
\hline$(22: 0 / 10: 0) P C$ & $\mathrm{~L}_{\beta}^{\mathrm{mi}}$ & 20 & 0.410 & 0.473 & 0.194 & 72 \\
\hline (O-20:0/O-12:0)PC & $\mathrm{L}_{\beta}^{\mathrm{mi}}$ & 23 & 0.420 & 0.485 & 0.204 & 73 \\
\hline (O-12:0/0-20:0)PC & $\mathrm{L}_{\beta}^{\mathrm{mi}}$ & 14 & 0.415 & 0.479 & 0.199 & 73 \\
\hline
\end{tabular}

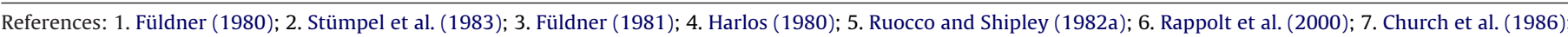

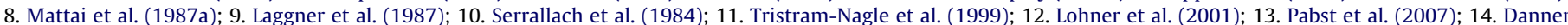

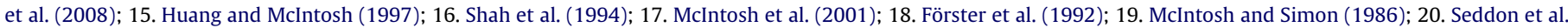

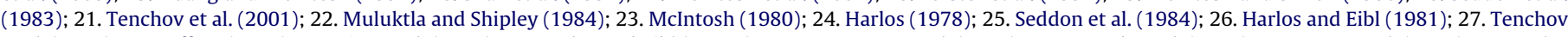

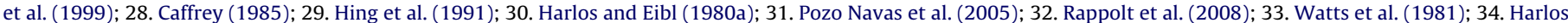

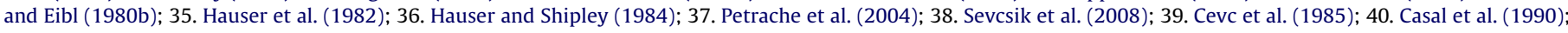

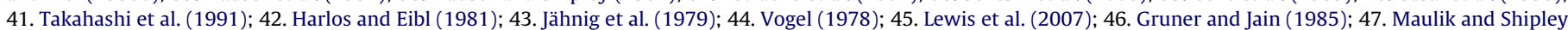

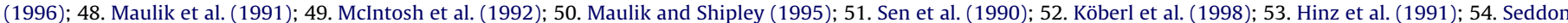

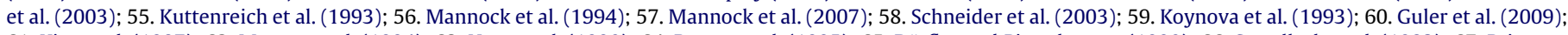

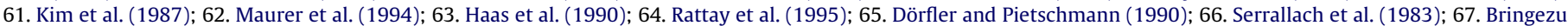
et al. (2000); 68. Wilkinson et al. (1987); 69. Shah et al. (1990); 70. Hui et al. (1984); 71. McIntosh et al. (1984); 72. Lewis et al. (1994); 73. Mattai et al. (1987b).

a Sample with $80 \mathrm{wt} \%$ water.

\subsection{Hexagonal chain packing}

Hexagonal chain packing (six nearest neighbours) is the common mode of chain packing in the $\mathrm{L}_{\beta}$ gel phase of phosphatidylethanolamines (McIntosh, 1980; Seddon et al., 1983, 1984) and certain other phospholipids (Jähnig et al., 1979; Watts et al., 1981; Hauser et al., 1982), in the $\mathrm{P}_{\beta^{\prime}}$ intermediate gel phase of diacyl phosphatidylcholines and phosphatidylglycerols (Tardieu et al., 1973; Janiak et al., 1976, 1979; Lohner et al., 2001), and in the $\mathrm{L}_{\beta}^{\mathrm{i}}$ interdigitated gel phase of dialkyl phosphatidylcholines (Laggner et al., 1987; Kim et al., 1987). It is also found above the $\mathrm{R}_{\mathrm{I}}-\mathrm{R}_{\mathrm{II}}$ rotator phase transition in $n$-alkanes (Sirota et al., 1993). Table 6 gives the wide-angle chain reflections $\left(s_{10}=s_{11}\right)$ and the chain packing parameters deduced from the hexagonal subcell.

It is notable that the gel phases of diacyl and dialkyl glycoglycerolipids, $(n: 0)_{2}$ GlcDG, $(0-n: 0)_{2}$ GalDG, etc., are all of the $\mathrm{L}_{\beta}$ type with hexagonally packed chains (Sen et al., 1990; Hinz et al., 1991). None are of the $L_{\beta^{\prime}}$ type with distorted hexagonal packing and tilted chains. Note, however, that the gel phases are mostly metastable for these lipids, and a crystalline $L_{c}$ phase is the stable state.

A variety of different interdigitated gel phases have hexagonal chain packing with untilted chains (see Table 6). These include the mixed interdigitated state, $\mathrm{L}_{\beta}^{\mathrm{mi}}$, that is formed by mixed-chain lipids such as (20:0/10:0)PC, in which one chain is twice the length of the other and extends across the entire hydrocarbon thickness of the bilayer. Several of the branched-chain lipids form partially interdigitated phases, that are designated $\mathrm{L}_{\beta, \mathrm{i}}$ and $\mathrm{L}_{\beta, \mathrm{I}}$ in Table 6 . The $\mathrm{L}_{\beta}{ }^{*}$ phase of the tetradecyl-branched phosphatidylethanolamine (2Ttd16:0/0-16:0)PE is thought to have interdigitated head groups (Bringezu et al., 2000). The conventional $\mathrm{L}_{\beta}^{\mathrm{i}}$ interdigitated gel phase of phosphatidylglycerol, (16:0) 2 PG, is induced by interfacial adsorption of the amphiphilic cation Tris (Wilkinson et al., 1987). The interdigitated gel phase that is formed by lysylphosphatidylglycerol, (16:0) ${ }_{2}$ PGLys, is possibly metastable and coexists as a minority phase with the $\mathrm{L}_{\beta^{\prime}}$ or $\mathrm{P}_{\beta^{\prime}}$ gel phase. 


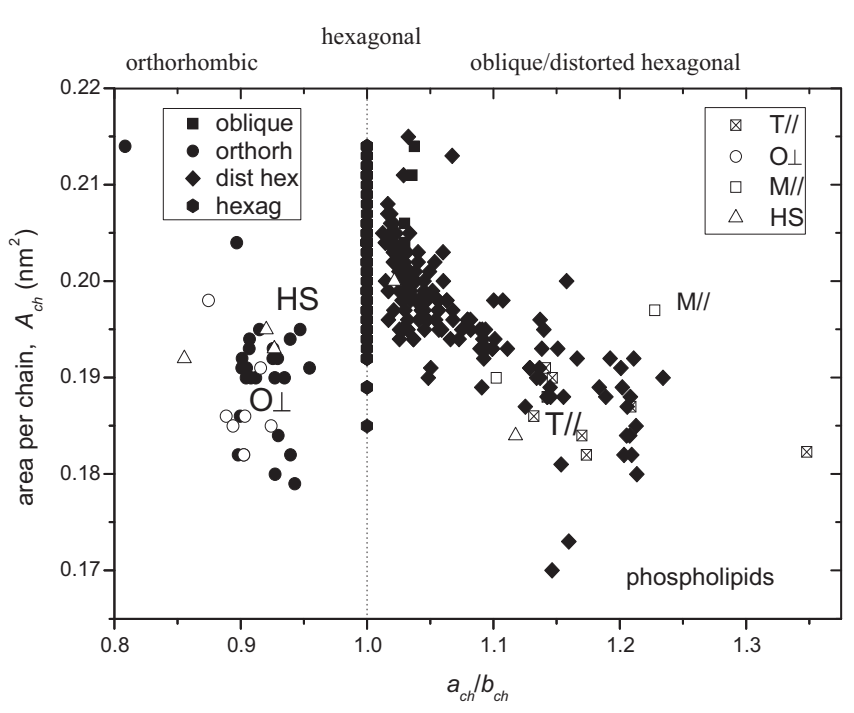

Fig. 3. Comparison of chain packing in gel and crystalline lamellar phases of phospholipids (solid symbols) with that in single crystals (open symbols). The area per chain, $A_{c h}$, is plotted against the ratio, $a_{c h} / b_{c h}$, of nearest and next-nearest neighbour chain-chain spacings. For orthorhombic packing: $a_{c h} / b_{c h}<1$; for distorted hexagonal, and also oblique packing: $a_{c h} / b_{c h}>1$; and for hexagonal packing $a_{c h} / b_{c h}=1$.

\section{Conclusion}

I have attempted to classify the chain packing in ordered phases of hydrated phospholipid and glycolipid bilayers according to the underlying subcells. For the gel and subgel phases, this is possible according to the scheme given by Tenchov et al. (2001) (see Fig. 2). The principal uncertainty occurs in distinguishing distorted hexagonal ( $2 n n)$ from orthorhombic ( $4 n n)$ packing, and in some cases I have reversed assignments to accord better with the relative intensities of the wide-angle reflections.

The situation is less straightforward for the $\mathrm{L}_{c}$ phases, because the three-dimensional crystallinity makes it more difficult to identify reflections that originate solely from the two-dimensional chain sublattice. For this reason, as already alluded to, some of these assignments are only tentative.

Fig. 3 summarises the results on chain packing for phospholipid bilayers; Fig. 4 does the same for glycolipid bilayers. The area per chain, $A_{c h}$, is classified according to the departure from hexagonal packing as reflected by the asymmetry, $a_{c h} / b_{c h}$, between nearest and next-nearest neighbour chain spacings. For hexagonal packing $a_{c h} / b_{c h}=1$; for distorted hexagonal (2nn) packing: $a_{c h} / b_{c h}>1$; and for orthorhombic ( $4 \mathrm{nn}$ ) packing: $a_{c h} / b_{c h}<1$. According to the convention used here, $a_{c h} / b_{c h}>1$ for the oblique subcells that characterise triclinic or monoclinic chain packing in crystals. In Figs. 3 and 4, the data for hydrated bilayers (solid symbols) are compared with those for lipid single crystals (see Table 1) that are given by the open symbols, as a point of reference.

The data are, of course, more numerous for phospholipids than for glycolipids. Nonetheless, it is notable that orthorhombic (4nn) packing is rare in glycolipids (only two $\mathrm{L}_{\mathrm{c}}$ phases), whereas it occurs relatively frequently for the metastable $m \mathrm{~L}_{\beta}$ phases of phospholipids other than phosphatidylcholine. On the other hand, oblique chain subcells are relatively rare in phospholipid bilayers, occurring only for lipids with branched chains and not invariably for branched-chain lipids. Hexagonal chain packing is frequent for both phospholipids and glycolipids, $\mathrm{L}_{\beta}$ being the usual gel phase for most lipids other than saturated symmetric-chain phosphatidylcholines. Distorted hexagonal (2nn) packing occurs frequently for phospholipids, but is restricted to the $\mathrm{L}_{\beta^{\prime}}$ and $\mathrm{L}_{\mathrm{c}^{\prime}}$ phases of phosphatidylcholines and $\mathrm{L}_{\beta^{\prime}}$ phases of phosphatidylglycerols. As

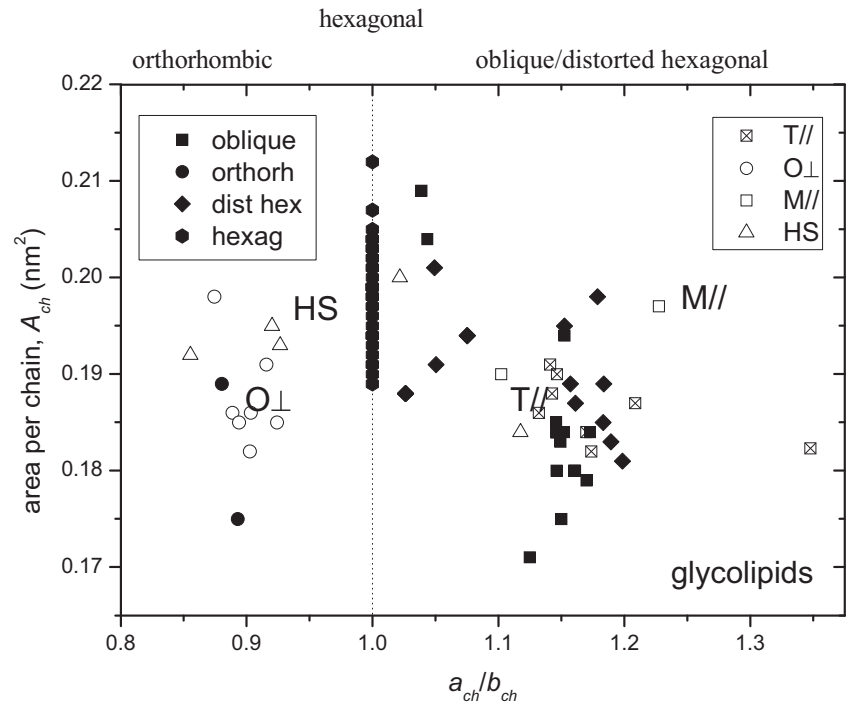

Fig. 4. Comparison of chain packing in gel and crystalline lamellar phases of glycolipids (solid symbols) with that in single crystals (open symbols). The area per chain, $A_{c h}$, is plotted against the ratio, $a_{c h} / b_{c h}$, of nearest and next-nearest neighbour chain-chain spacings. For orthorhombic packing: $a_{c h} / b_{c h}<1$; for distorted hexagonal, and also oblique packing: $a_{c h} / b_{c h}>1$; and for hexagonal packing $a_{c h} / b_{c h}=1$.

discussed above, it is not certain whether this packing mode occurs in $\mathrm{L}_{\mathrm{c}}$ phases of some glycolipids. It has not been found in a crystal structure.

For glycolipid bilayers, the areas per chain in the gel phases (all of which have hexagonal chain packing, i.e., $\mathrm{L}_{\beta}$ ), are mostly larger than those for the reference crystal structures, as is expected. In the $\mathrm{L}_{\mathrm{c}}$ phases the values of $A_{c h}$ cluster about those for the crystal structures, but with a few outliers. For phospholipid bilayers, the gel phases also have larger areas per molecule than for the reference crystal structures, but those for the subgel and low-temperature $m \mathrm{~L}_{\beta^{\prime}}$ phases cluster about the crystal values. In addition, the packing asymmetry, $a_{c h} / b_{c h}$, decreases according to this increasing trend in $A_{c h}$ on going from subgel to gel.

Unlike the chains, the head groups in gel-phase bilayers are dynamically disordered. In subgel phases and crystalline $\mathrm{L}_{c}$ phases, however, the head groups are also ordered. For the $\mathrm{L}_{\mathrm{c}^{\prime}}$ subgel phase of phosphatidylcholines (unlike for the $\mathrm{L}_{c}$ phases), a head-group sublattice can be identified and the head-group separations can be determined. Details are given in Appendix A.

\section{Appendix A. Head-group packing: Molecular sublattice in $\mathbf{L}_{\mathbf{c}^{\prime}}$ phases}

For subgel phases $\left(\mathrm{L}_{\mathrm{c}^{\prime}}\right)$, the chain lattice in the bilayer plane is specified by the centred oblique unit-cell parameters $a, b$ and $\gamma$ (see Fig. A1). It is related to the chain sublattice $\left(a_{s}, b_{s}, \gamma_{s}\right)$ in the plane perpendicular to the chain axis (see Appendix B) by the angle $\left(\theta_{t}\right)$ and direction $(\omega)$ of tilt of the chains relative to the bilayer normal.

The whole lipid molecule - not only the chains - is twodimensionally ordered in subgel phases. In general, the molecular lattice of the lipid head groups is also specified by an oblique lattice, which must be commensurate with that of the chains. For the subgel phase of $(16: 0)_{2} \mathrm{PC}$, the unit cell of the head-group lattice is given by vectors connecting the origin to points $(a,-b)$ and $(a / 2,3 b / 2)$ of the chain lattice (Raghunathan and Katsaras, 1995). The unit cell parameters of the molecular lattice are therefore given by:

$a_{\text {mol }}^{2}=a^{2}+b^{2}+2 a b \cos \gamma$

$b_{\text {mol }}^{2}=\frac{\left(a^{2}+9 b^{2}\right)}{4}-\left(\frac{3 a b}{2}\right) \cos \gamma$ 


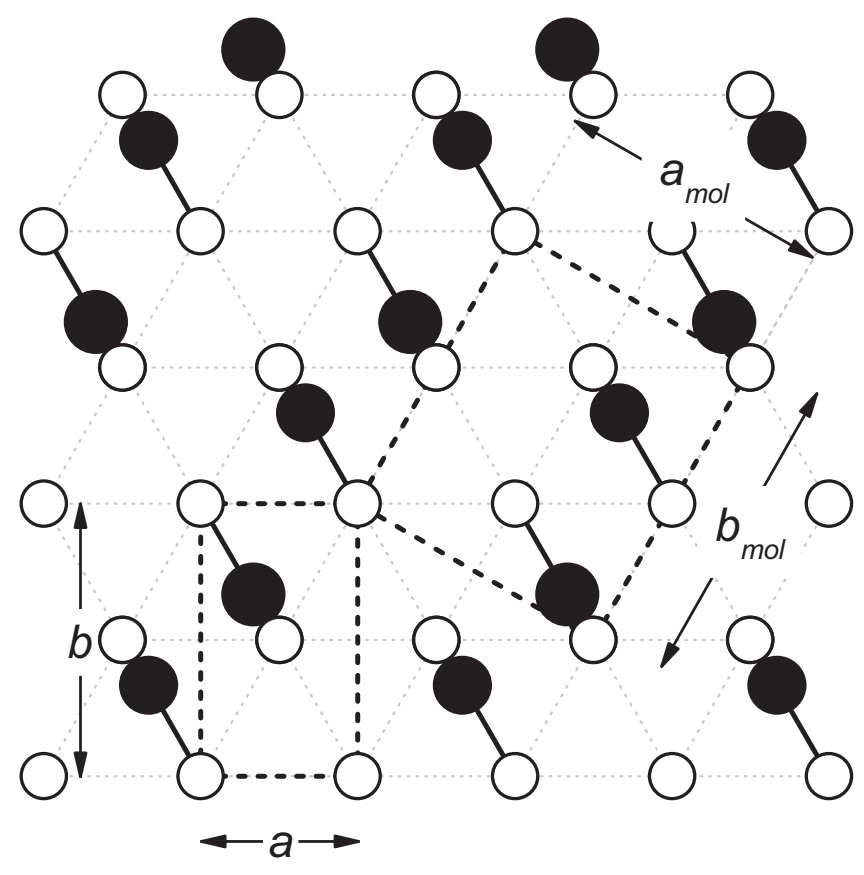

Fig. A1. Relation between the molecular (i.e., head-group) and chain lattices in the plane of the membrane for the phosphatidylcholine $\mathrm{L}_{\mathrm{c}^{\prime}}$ phase. Chains are indicated by open circles and head groups by solid circles. Two chains are connected by a solid line to form one lipid molecule. The chain unit cell has sides $a$ and $b$; the molecular unit cell has sides $a_{m o l}$ and $b_{m o l}$, and is twice the size.

See Raghunathan and Katsaras (1995) and Katsaras et al. (1995).

$\cos ^{2} \gamma_{m o l}=\frac{3 b^{2}-a^{2}+2 a b \cos \gamma}{2 a_{m o l} b_{m o l}}$

From Eq. (A3), it is clear that molecular and chain lattices are both rectangular only if $a=\sqrt{3} b$, i.e., the chain lattice in the plane of the bilayer must be hexagonal for this to hold. Otherwise one (or both) of the two lattices must be oblique. The chain sublattice in the $\mathrm{L}_{\mathrm{c}^{\prime}}$ phase of $(16: 0)_{2} \mathrm{PC}$ is actually slightly oblique (see Appendix $\mathrm{B}$ ).
The condition that the head-group lattice is rectangular (which is approximately the case for $(16: 0)_{2} \mathrm{PC}$ - Raghunathan and Katsaras (1995)) is from Eq. (A3):

$a=b\left(\sqrt{3+\cos ^{2} \gamma}+\cos \gamma\right)$

which requires a particular combination of unit-cell parameters for the chain lattice.

As for the chain lattice, the deviations of the molecular lattice from rectangular are small for saturated phosphatidylcholines. Frequently, the only reflections with appreciable intensity are the two corresponding to the (10) and (1 1 ) plus ( $\overline{1} 1$ ) lattice spacings, where no splitting of the latter is resolved. From Eqs. (A1) and (A2), the unit-cell dimensions of the chain and molecular lattices are then related approximately by (Raghunathan and Katsaras, 1996):

$a_{\mathrm{mol}} \approx \sqrt{a^{2}+b^{2}}$

$b_{\text {mol }} \approx \frac{\sqrt{a^{2}+9 b^{2}}}{2}$

where $a$ and $b$ are the unit cell dimensions of the centredrectangular chain lattice (in the membrane plane). For a tilt, $\theta_{\mathrm{t}}$, in the direction of nearest neighbour chains: $a=2 s_{20}$ and $b=b_{c h} / \cos \theta_{\mathrm{t}}$, where $s_{20}$ is the spacing of the $(20)$ chain planes, and $b_{c h}$ is the closest distance between nearest-neighbour chains. The closest separations, $a_{H G}$ and $b_{H G}$, between head groups are given by:

$a_{H G}=\frac{a_{m o l}}{2}$

$b_{H G}(\equiv b)=\sqrt{\left(4 b_{m o l}^{2}-a_{m o l}^{2}\right) / 8}$

where $a_{H G}$ corresponds to nearest neighbours in phosphatidylcholines. The area per lipid is given by:

$A_{l}=\frac{a_{m o l} b_{m o l}}{2}(\approx a b)$

because there are two lipids per unit cell in the molecular lattice and two chains per unit cell in the chain lattice.

Wide-angle reflections that correspond to the molecular sublattice have been detected for the subgel phases of several

Table A1

Wide-angle reflections of the molecular sublattice and head-group spacings in $\mathrm{L}_{\mathrm{c}^{\prime}}$ subgel phases.

\begin{tabular}{|c|c|c|c|c|c|c|c|c|c|}
\hline Lipid & Phase & $T\left({ }^{\circ} \mathrm{C}\right)$ & $s_{10}(\mathrm{~nm})$ & $s_{11}(\mathrm{~nm})$ & $a_{H G}(\mathrm{~nm})$ & $b_{H G}(\mathrm{~nm})$ & $A_{l}\left(\mathrm{~nm}^{2}\right)$ & $\theta_{\mathrm{t}}\left(^{\circ}\right)$ & Ref. \\
\hline \multirow[t]{7}{*}{$(16: 0)_{2} \mathrm{PC}$} & \multirow[t]{7}{*}{$\mathrm{L}_{\mathrm{c}^{\prime}}$} & 5 & 1.000 & 0.675 & 0.500 & 0.542 & 0.457 & 35 & 1 \\
\hline & & 5 & 1.000 & 0.678 & 0.500 & 0.548 & 0.461 & 35 & 2 \\
\hline & & 7 & 1.000 & 0.680 & 0.500 & 0.552 & 0.464 & 35 & 3,4 \\
\hline & & 8 & 1.000 & 0.681 & 0.500 & 0.554 & 0.465 & 36 & 5 \\
\hline & & 10 & 1.020 & 0.681 & 0.510 & 0.537 & 0.467 & 33 & 6 \\
\hline & & 10 & 0.980 & 0.680 & 0.490 & 0.571 & 0.463 & 34 & 7 \\
\hline & & $<13$ & 1.010 & $-{ }^{\mathrm{a}}$ & 0.505 & 0.532 & 0.458 & 34 & 8 \\
\hline \multirow[t]{2}{*}{$(18: 0)_{2} \mathrm{PC}$} & \multirow[t]{2}{*}{$\mathrm{L}_{\mathrm{C}^{\prime}}$} & -4 & & 0.680 & & & & & 9 \\
\hline & & 4 & 1.010 & 0.680 & 0.505 & 0.543 & 0.464 & 35 & 3 \\
\hline$(\mathrm{i} 17: 0)_{2} \mathrm{PC}$ & $\mathrm{L}_{\mathrm{c}}$ & $<19$ & 0.910 & 0.631 & 0.455 & 0.529 & 0.398 & 18 & 8 \\
\hline$(\mathrm{i} 20: 0)_{2} \mathrm{PC}$ & $\mathrm{L}_{\mathrm{c}^{\prime}}$ & $<44$ & 1.090 & 0.682 & 0.545 & 0.483 & 0.476 & 37 & 8 \\
\hline \multirow[t]{2}{*}{$(14: 0 / 16: 0) \mathrm{PC}$} & \multirow[t]{2}{*}{$\mathrm{L}_{\mathrm{c}^{\prime}}$} & -3 & 0.98 & $0.63^{\mathrm{b}}$ & 0.49 & 0.47 & 0.40 & 24 & 10 \\
\hline & & 15 & 0.98 & $0.63^{\mathrm{b}}$ & 0.49 & 0.47 & 0.40 & 25 & 11 \\
\hline$(14: 0 / 18: 0) \mathrm{PC}$ & $\mathrm{L}_{\mathrm{C}^{\prime}}$ & 4 & 0.998 & 0.675 & 0.499 & 0.544 & 0.457 & 35 & 2 \\
\hline \multirow[t]{2}{*}{$(16: 0 / 14: 0) \mathrm{PC}$} & \multirow[t]{2}{*}{$\mathrm{L}_{\mathrm{C}^{\prime}}$} & -9 & 0.950 & 0.673 & 0.475 & 0.585 & 0.453 & 30 & 10 \\
\hline & & 3 & 0.996 & 0.674 & 0.498 & 0.543 & 0.456 & 34 & 2 \\
\hline \multirow[t]{2}{*}{$(18: 0 / 16: 0) \mathrm{PC}$} & \multirow[t]{2}{*}{$\mathrm{L}_{\mathrm{c}^{\prime}}$} & 4 & 0.918 & 0.670 & 0.459 & 0.612 & 0.450 & 31 & 2 \\
\hline & & 23 & 0.918 & 0.670 & 0.459 & 0.612 & 0.450 & 31 & 2 \\
\hline $1,3-(14: 0)_{2} \mathrm{PC}$ & $\mathrm{L}_{\mathrm{c}^{\prime}}$ & 2 & 0.973 & 0.669 & 0.487 & 0.553 & 0.448 & 28 & 2 \\
\hline \multirow[t]{2}{*}{$1,3-(16: 0)_{2} \mathrm{PC}$} & \multirow[t]{2}{*}{$\mathrm{L}_{\mathrm{C}^{\prime}}$} & 5 & 0.963 & 0.670 & 0.482 & 0.565 & 0.449 & 28 & 2 \\
\hline & & 6 & 0.96 & 0.66 & 0.48 & 0.55 & 0.44 & 38 & 12 \\
\hline 1,3-(18:0/14:0)PC & $\mathrm{L}_{\mathrm{C}^{\prime}}$ & 5 & 0.982 & 0.669 & 0.491 & 0.545 & 0.449 & 36 & 2 \\
\hline $1,3-(18: 0 / 16: 0) \mathrm{PC}$ & $\mathrm{L}_{\mathrm{c}^{\prime}}$ & 2 & 0.982 & 0.664 & 0.491 & 0.534 & 0.443 & 39 & 2 \\
\hline
\end{tabular}

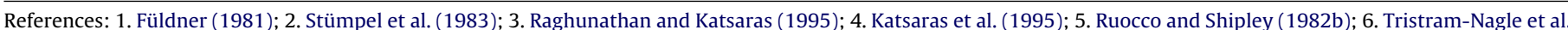

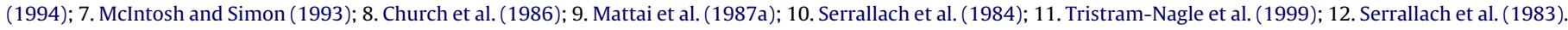

a $b_{\text {mol }}=0.906 \mathrm{~nm}$ (Church et al., 1986).

b Tentative assignment. 
phosphatidylcholines. These are listed, together with their assignments, in Table A1. The corresponding separations ( $a_{H G}$ and $b_{H G}$ ) between head groups, the area per lipid molecule $\left(A_{l}\right)$ in the lamellar plane, and the chain tilt $\left(\theta_{t}\right)$ are also given in the same table.

\section{Appendix B. Oblique chain sublattice in $\mathbf{L}_{\mathbf{c}^{\prime}}$ subgel phases}

Experiments with aligned samples in the $\mathrm{L}_{\mathrm{c}^{\prime}}$ phase of phosphatidylcholines are able to resolve separate 11 and $1 \overline{1}$ chain reflections, which remain unresolved from one another in powder diffraction (see Katsaras et al., 1995). This indicates a slight obliquity of the centred rectangular lattice for $\mathrm{L}_{\mathrm{c}^{\prime}}$ phases. Because these deviations are small, this is best treated as a centred oblique chain sublattice that is chosen to be related directly to the centred rectangular chain lattices. The short spacings, $s_{h k}$, in the plane perpendicular to the chain axes are then given by Eq. (3) of the main text, with unit-cell dimensions $a_{s}, b_{s}$ and $\gamma_{s}$. The immediateneighbour chain spacing that corresponds to the $\mathbf{b}_{\mathrm{s}}$-axis of the unit-cell is given by:

$b_{c h} \equiv b_{s}=\frac{2 s_{20}}{\sqrt{2 s_{20}^{2}\left(s_{11}^{-2}+s_{11}^{-2}\right)-s_{20}^{4}\left(s_{11}^{-2}-s_{\overline{1} 1}^{-2}\right)^{2}-1}}$

The other two chain spacings are given by the semidiagonals of the centred oblique unit cell:

$a_{c h, 1}=\frac{s_{20}}{s_{11}} b_{c h}$

$a_{c h, 2}=\frac{s_{20}}{s_{11}} b_{c h}$

The area per chain in the plane perpendicular to the chain axis is given by the left-hand equality in Eq. (8) of the main text:

$A_{c h}=s_{20} b_{c h}$

where $b_{c h}$ is given by Eq. (A10).

For the $\mathrm{L}_{\mathrm{c}^{\prime}}$ subgel phase of $(16: 0)_{2} \mathrm{PC}$ at $65 \% \mathrm{RH}$ and $17 \pm 2{ }^{\circ} \mathrm{C}$, the chain short spacings are: $s_{20}=0.44 \mathrm{~nm}, s_{11}=0.39 \mathrm{~nm}$, and $s_{\overline{1} 1}=0.38 \mathrm{~nm}$ (Katsaras et al., 1995; Katsaras, 1995), yielding: $a_{c h, 1}=0.48 \mathrm{~nm}, a_{c h, 2}=0.50 \mathrm{~nm}, b_{c h}=0.43 \mathrm{~nm}$, and $A_{c h}=0.19 \mathrm{~nm}^{2}$.

\section{References}

Abrahamsson, S., Dahlén, B., Löfgren, H., Pascher, I., 1978. Lateral packing of hydrocarbon chains. Prog. Chem. Fats Other Lipids 16, 125-143.

Abrahamsson, S., Dahlén, B., Pascher, I., 1977. Molecular arrangements in glycosphingolipids - crystal structure of glucosylphytosphingosine hydrochloride. Acta Cryst. Sect. B 33, 2008-2013.

Blaurock, A.E., McIntosh, T.J., 1986. Structure of the crystalline bilayer in the subgel phase of dipalmitoylphosphatidylglycerol. Biochemistry 25, 299-305.

Bringezu, F., Rapp, G., Dobner, B., Nuhn, P., Brezesinski, G., 2000. Structures and phase transitions in aqueous dispersions of branched-chain glycerophosphoethanolamines. Phys. Chem. Chem. Phys. 2, 4509-4514.

Bringezu, F., Rapp, G., Dobner, B., Nuhn, P., Brezesinski, G., 2001. Stability and structures of liquid crystalline phases formed by branched-chain phospholipid diastereomers. J. Phys. Chem. B 105, 1901-1907.

Bunn, C.W., 1939. The crystal structure of long-chain normal paraffin hydrocarbons. The "shape" of the $>\mathrm{CH}_{2}$ group. Transact. Faraday Soc. 35, 482-491.

Caffrey, M., 1985. Kinetics and mechanisms of the lamellar gel/lamellar liquid-crystal and lamellar/inverted hexagonal phase transition in phosphatidylethanolamine: a real-time X-ray diffraction study using synchrotron radiation. Biochemistry $24,4826-4844$.

Casal, H.L., Mantsch, H.H., Demel, R.A., Paltauf, F., Lipka, G., Hauser, H., 1990. Phase behavior and physical-chemical properties of $N$-methylated phosphatidylserine. J. Am. Chem. Soc. 112, 3887-3895.

Cevc, G., Seddon, J.M., Marsh, D., 1985. Thermodynamic and structural properties of phosphatidylserine bilayer membranes in the presence of lithium ions and protons. Biochim. Biophys. Acta 814, 141-150.

Church, S.E., Griffiths, D.J., Lewis, R.N.A.H., McElhaney, R.N., Wickman, H.H., 1986. $\mathrm{X}$-ray structure study of thermotropic phases in isoacylphosphatidylcholine multibilayers. Biophys. J. 49, 597-605.

Dahlen, B., Lunden, B.M., Pascher, I., 1976. Crystal structure of 2-DLhydroxytetradecanoic acid. Acta Crystallogr. Sect. B 32, 2059-2063.
Dahlen, B., Pascher, I., 1972. Molecular arrangements in sphingolipids - crystal structure of $N$-tetracosanoylphytosphingosine. Acta Cryst. Sect. B 28, 2396-2404.

Danner, S., Pabst, G., Lohner, K., Hickel, A., 2008. Structure and thermotropic behavior of the Staphylococcus aureus lipid lysyl-dipalmitoylphosphatidylglycerol. Biophys. J. 94, 2150-2159.

Denicolo, I., Doucet, J., Craievich, A.F., 1983. X-ray study of the rotator phase of paraffins(III) - even-numbered paraffins $\mathrm{C}_{18} \mathrm{H}_{38}, \mathrm{C}_{20} \mathrm{H}_{42}, \mathrm{C}_{22} \mathrm{H}_{46}, \mathrm{C}_{24} \mathrm{H}_{50}$, and $\mathrm{C}_{26} \mathrm{H}_{54}$ J. Chem. Phys. 78, 1465-1469.

Dorset, D.L., 1976. Aliphatic chain packing in 3 crystalline polymorphs of a saturated racemic phosphatidylethanolamine - quantitative electron-diffraction study. Biochim. Biophys. Acta 424, 396-403.

Doucet, J., Denicolo, I., Craievich, A.F., 1981. X-ray study of the rotator phase of the odd-numbered paraffins $\mathrm{C}_{17} \mathrm{H}_{36}, \mathrm{C}_{19} \mathrm{H}_{40}$, and $\mathrm{C}_{21} \mathrm{H}_{44}$. J. Chem. Phys. 75 1523-1529.

Dörfler, H.-D., Pietschmann, N., 1990. Phase diagrams and structures of lecithin/water systems with branched lecithin components. Colloid Polym. Sci. 268, 578-588.

Elder, M., Hitchcock, P., Mason, R., Shipley, G.G., 1977. A refinement analysis of the crystallography of the phospholipid, 1,2-dilauroyl-DLphosphatidylethanolamine, and some remarks on lipid-lipid and lipid-protein interactions. Proc. R. Soc. Lond. A 354, 157-170.

Förster, G., Brezesinski, G., Wolgast, S., 1992. Polymorphism of phosphatidylcholines varied in the hydrophobic part. Progr. Colloid Polym. Sci. 89, 271-273.

Füldner, H., 1981. Characterization of a third phase transition in multilamellar dipalmitoyllecithin liposomes. Biochemistry 20, 5707-5710.

Füldner, H.H., 1980. Molekulare Ordnungen in reinen Lipid- und Lipid-ProteinModellmembranen, Thesis/Dissertation, Universität Ulm, Germany.

Garidel, P., Richter, W., Rapp, G., Blume, A., 2001. Structural and morphological investigations of the formation of quasi-crystalline phases of 1,2 dimyristoyl-sn-glycero-3-phosphoglycerol (DMPG). Phys. Chem. Chem. Phys. 3, 1504-1513.

Gruner, S.M., Jain, M.K., 1985. X-ray diffraction demonstrates that phosphatidyldiacylglycerol and phosphatidylcholesterol are not lamellar above the main transition temperature. Biochim. Biophys. Acta 818, 352-355.

Guler, S.D., Ghosh, D.D., Pan, J., Mathai, J.C., Zeidel, M.L., Nagle, J.F., Tristram-Nagle, S., 2009. Effects of ether vs. ester linkage on lipid bilayer structure and water permeability. Chem. Phys. Lipids 160, 33-44.

Haas, N.S., Sripada, P.K., Shipley, G.G., 1990. Effect of chain-linkage on the structure of phosphatidyl choline bilayers. Hydration studies of 1-hexadecyl 2-palmitoylsn-glycero-3-phosphocholine. Biophys. J. 57, 117-124.

Harlos, K., 1978. Pretransitions in the hydrocarbon chains of phosphatidylethanolamines. Biochim. Biophys. Acta 511, 348-355.

Harlos, K., 1980. Einfluss von Struktur und Oberflächenladungen auf die Eigenschaften von Phospholipid/Wassersystemen, Thesis/Dissertation, Technische Universität Carola-Wilhelmina, Braunschweig, Germany.

Harlos, K., Eibl, H., 1980a. Influence of calcium on phosphatidylethanolamine: an investigation of the structure at high pH. Biochim. Biophys. Acta 601, 113-122.

Harlos, K., Eibl, H., 1980b. Influence of calcium on phosphatidylglycerol. Two separate lamellar structures. Biochemistry 19, 895-899.

Harlos, K., Eibl, H., Pascher, I., Sundell, S., 1984. Conformation and packing properties of phosphatidic acid - the crystal structure of monosodium dimyristoylphosphatidate. Chem. Phys. Lipids 34, 115-126.

Harlos, K., Eibl, H.J., 1981. Hexagonal phases in phospholipids with saturated chains: phosphatidylethanolamines and phosphatidic acids. Biochemistry 20 2888-2892.

Hauser, H., Pascher, I., Sundell, S., 1980. Conformation of phospholipids - crystal structure of a lysophosphatidylcholine analogue. J. Mol. Biol. 137, 249-264.

Hauser, H., Paltauf, F., Shipley, G.G., 1982. Structure and thermotropic behavior of phosphatidylserine bilayer membranes. Biochemistry 21, 1061-1067.

Hauser, H., Shipley, G.G., 1983. Interactions of monovalent cations with phosphatidylserine bilayer membranes. Biochemistry 22, 2171-2178.

Hauser, H., Shipley, G.G., 1984. Interactions of divalent cations with phosphatidylserine bilayer membranes. Biochemistry 23, 34-41.

Hing, F.S., Maulik, P.R., Shipley, G.G., 1991. Structure and interactions of ether- and ester-linked phosphatidylethanolamine. Biochemistry 30, 9007-9015.

Hinz, H.-J., Kuttenreich, H., Meyer, R., Renner, M., Fründ, R., Koynova, R., Boyanov A.I., Tenchov, B.G., 1991. Stereochemistry and size of sugar head groups determine structure and phase behavior of glycolipid membranes - densitometric, calorimetic, and X-ray studies. Biochemistry 30, 5125-5138.

Huang, C., McIntosh, T.J., 1997. Probing the ethanol-induced chain interdigitations in gel-state bilayers of mixed-chain phosphatidylcholines. Biophys. J. 72 2702-2709.

Hui, S.W., Mason, J.T., Huang, C.-H., 1984. Acyl chain interdigitation in saturated mixed-chain phosphatidylcholine bilayer dispersions. Biochemistry 23 , 5570-5577.

Janiak, M.J., Small, D.M., Shipley, G.G., 1976. Nature of the thermal pretransition of synthetic phospholipids: dimyristoyl-and dipalmitoyllecithin. Biochemistry 15 , 4575-4580.

Janiak, M.J., Small, D.M., Shipley, G.G., 1979. Temperature and composition dependence of the structure of hydrated dimyristoyl lecithin. J. Biol. Chem. 254 6068-6078.

Jähnig, F., Harlos, K., Vogel, H., Eibl, H., 1979. Electrostatic interactions at charged lipid membranes. Electrostatically induced tilt. Biochemistry 18 , 1459-1468.

Katsaras, J., 1995. Structure of the subgel $\left(\mathrm{L}_{\mathrm{C}^{\prime}}\right)$ and gel $\left(\mathrm{L}_{\beta^{\prime}}\right)$ phases of oriented dipalmitoylphosphatidylcholine multibilayers. J. Phys. Chem. 99, 4141-4147. 
Katsaras, J., Raghunathan, V.A., Dufourc, E.J., Dufourcq, J., 1995. Evidence for a twodimensional molecular lattice in subgel phase DPPC bilayers. Biochemistry 34 , 4684-4688.

Kim, J.T., Mattai, J., Shipley, G.G., 1987. Gel phase polymorphism in ether-linked dihexadecylphosphatidylcholine bilayers. Biochemistry 26, 6592-6598.

Koynova, R., Tenchov, B., Todinova, S., Quinn, P.J., 1995. Rapid reversible formation of a metastable subgel phase in saturated diacylphosphatidylcholines. Biophys. J. 68, 2370-2375.

Koynova, R.D., Tenchov, B., Kuttenreich, H., Hinz, H.-J., 1993. Structure and phase behavior of a charged glycolipid (1,2-O-dialkyl-3-O- $\beta$-D-glucuronosylsn-glycerol). Biochemistry 32, 12437-12445.

Köberl, M., Hinz, H.-J., Rapp, G., 1998. Temperature scanning simultaneous smalland wide-angle X-ray scattering studies on glycolipid vesicles: areas, expansion coefficients and hydration. Chem. Phys. Lipids 91, 13-37.

Kuttenreich, H., Hinz, H.-J., Inczedy-Marcsek, M., Koynova, R., Tenchov, B., Laggner, P., 1988. Polymorphism of synthetic 1,2-O-dialkyl-3-O- $\beta$-D-galactosyl-snglycerols of different alkyl chain lengths. Chem. Phys. Lipids 47, 245-260.

Kuttenreich, H.L., Hinz, H.-J., Koynova, R., Tenchov, B., 1993. Different phase behaviour of the $s n-1$ and $s n-3$ stereoisomers of the glycolipid di-tetradecyl$\beta$-D-galactosylglycerol. Chem. Phys. Lipids 66, 55-62.

Laggner, P., Lohner, K., Degovics, G., Müller, K., Schuster, A., 1987. Structure and thermodynamics of the dihexadecylphosphatidylcholine-water system. Chem. Phys. Lipids 44, 31-60.

Lewis, R.N.A.H., McElhaney, R.N., Osterberg, F., Gruner, S.M., 1994. Enigmatic thermotropic phase behavior of highly asymmetric mixed-chain phosphatidylcholines that form mixed interdigitated gel phases. Biophys. J. 66, 207-216.

Lewis, R.N.A.H., Zweytick, D., Pabst, G., Lohner, K., McElhaney, R.N., 2007. Calorimetric, X-ray diffraction, and spectroscopic studies of the thermotropic phase behavior and organization of tetramyristoyl cardiolipin membranes. Biophys. J. 92, 3166-3177.

Lohner, K., Latal, A., Degovics, G., Garidel, P., 2001. Packing characteristics of a model system mimicking cytoplasmic bacterial membranes. Chem. Phys. Lipids 111, 177-192.

Mannock, D.A., Collins, M.D., Kreichbaum, M., Harper, P.E., Gruner, S.M., McElhaney, R.N., 2007. The thermotropic phase behaviour and phase structure of a homologous series of racemic $\beta$-D-galactosyl dialkylglycerols studied by differential scanning calorimetry and X-ray diffraction. Chem. Phys. Lipids 148, 26-50.

Mannock, D.A., McElhaney, R.N., Harper, P.E., Gruner, S.M., 1994. Differential scanning calorimetry and X-ray diffraction studies of the thermotropic phase behavior of the diastereomeric di-tetradecyl- $\beta$-D-galactosyl glycerols and their mixture. Biophys. J. 66, 734-740.

Mattai, J., Shipley, G.G., 1986. The kinetics of formation and structure of the lowtemperature phase of 1-stearoyl-lysophosphatidylcholine. Biochim. Biophys. Acta 859, 257-265.

Mattai, J., Sripada, P.K., Shipley, G.G., 1987a. Mixed-chain phosphatidylcholine bilayers: structure and properties. Biochemistry 26, 3287-3297.

Mattai, J., Witzke, N.M., Bittman, R., Shipley, G.G., 1987b. Structure and thermotropic properties of hydrated 1-eicosyl-2-dodecyl-rac-glycero-3-phosphocholine and 1-dodecyl-2-eicosyl-rac-glycero-3-phosphocholine bilayer membranes. Biochemistry 26, 623-633.

Maulik, P.R., Shipley, G.G., 1995. X-ray diffraction and calorimetric study of $\mathrm{N}$ lignoceryl sphingomyelin membranes. Biophys. J. 69, 1909-1916.

Maulik, P.R., Shipley, G.G., 1996. N-palmitoyl sphingomyelin bilayers: structure and interactions with cholesterol and dipalmitoylphosphatidylcholine. Biochemistry 35, 8025-8034.

Maulik, P.R., Sripada, P.K., Shipley, G.G., 1991. Structure and thermotropic properties of hydrated $\mathrm{N}$-stearoyl sphingomyelin bilayer membranes. Biochim. Biophys. Acta 1062, 211-219.

Maurer, N., Prenner, E., Paltauf, F., Glatter, O., 1994. Phase-behavior of the antineoplastic ether lipid 1-O-octadecyl-2-O-methyl-glycerol-3-phosphocholine. Biochim. Biophys. Acta 1192, 167-176.

McIntosh, T.J., 1980. Differences in hydrocarbon chain tilt between hydrated phosphatidylethanolamine and phosphatidylcholine bilayers. Biophys. J. 29, 237-246.

McIntosh, T.J., Lin, H., Li, S., Huang, C.-H., 2001. The effect of ethanol on the phase transition temperature and the phase structure of monounsaturated phosphatidylcholines. Biochim. Biophys. Acta 1510, 219-230.

McIntosh, T.J., Simon, S.A., 1986. Area per molecule and distribution of water in fully hydrated dilauroylphosphatidylethanolamine bilayers. Biochemistry 25 , 4948-4952.

McIntosh, T.J., Simon, S.A., 1993. Contributions of hydration and steric (entropic) pressures to the interactions between phosphatidylcholine bilayers: experiments with the subgel phase. Biochemistry 32, 8374-8384.

McIntosh, T.J., Simon, S.A., Ellington Jr., J.C., Porter, N.A., 1984. New structural model for mixed-chain phosphatidylcholine bilayers. Biochemistry 23, 4038-4044.

McIntosh, T.J., Simon, S.A., Needham, D., Huang, C.-H., 1992. Structure and cohesive properties of sphingomyelin/cholesterol bilayers. Biochemistry 31 , 2012-2020.

Muluktla, S., Shipley, G.G., 1984. Structure and thermotropic properties of phosphatidylethanolamine and its $\mathrm{N}$-methyl derivatives. Biochemistry 23, 2514-2519.

Norman, N., Mathisen, H., 1972. Crystal structure of lower paraffins. V. Cell dimensions of nonane, decane, undecane, dodecane, tridecane, tetradecane, and hexadecane. Acta Chem. Scand. 26, 3913-3916.

Nyburg, S.C., Lüth, H., 1972. Octadecane - correction and refinement of structure given by Hayashida. Acta Cryst. Sect. B 28, 2992-2995.
Nyholm, P.-G., Pascher, I., Sundell, S., 1990. The effect of hydrogen bonds on the conformation of glycosphingolipids. Methylated and unmethylated cerebroside studied by X-ray single crystal analysis and model calculations. Chem. Phys. Lipids 52, 1-10.

O’Connell, A.M., Pascher, I., 1969. The crystal structure of triacetylsphingosine. Acta Cryst. B25, 2553-2561.

Pabst, G., Danner, S., Karmakar, S., Deutsch, G., Raghunathan, V.A., 2007. On the propensity of phosphatidylglycerols to form interdigitated phases. Biophys. J. 93, 513-525.

Pascher, I., Sundell, S., 1977. Molecular arrangements in sphingolipids - crystal structure of cerebroside. Chem. Phys. Lipids 20,175-191.

Pascher, I., Sundell, S., 1985. Interactions and space requirements of the phosphate head group in membrane lipids. The crystal structure of disodium lysophosphatidate dihydrate. Chem. Phys. Lipids 37, 241-250.

Pascher, I., Sundell, S., 1986. Membrane lipids: preferred conformational states and their interplay. The crystal structure of dilauroylphosphatidyl- $N, N-$ dimethylethanolamine. Biochim. Biophys. Acta 855, 68-78.

Pascher, I., Sundell, S., 1992. Molecular arrangements in sphingolipids - crysta structure of the ceramide $\mathrm{N}$-(2D,3D-dihydroxyoctadecanoyl)-phytosphingosine. Chem. Phys. Lipids 62, 79-86.

Pascher, I., Sundell, S., Eibl, H., Harlos, K., 1984. Interactions and space requirement of the phosphate head group of membrane lipids - the single crystal structures of a triclinic and a monoclinic form of hexadecyl-2-deoxyglycerophosphoric acid monohydrate. Chem. Phys. Lipids 35, 103-115.

Pascher, I., Sundell, S., Eibl, H. Harlos, K, 1986. The single-crystal structure of octadecyl-2-methyl-glycerophosphocholine monohydrate - a multilamellar structure with interdigitating head groups and hydrocarbon chains. Chem. Phys. Lipids 39, 53-64.

Pascher, I., Sundell, S., Harlos, K., Eibl, H., 1987. Conformation and packing properties of membrane lipids: The crystal structure of sodium dimyristoylphosphatidylglycerol. Biochim. Biophys. Acta 896, 77-88.

Pascher, I., Sundell, S., Hauser, H., 1981a. Glycerol conformation and molecular packing of membrane lipids. The crystal structure of 2,3-dilauroyl-D-glycerol. J. Mol. Biol. 153, 791-806.

Pascher, I., Sundell, S., Hauser, H., 1981b. Polar group interaction and molecular packing of membrane lipids - the crystal structure of lysophosphatidylethanolamine. J. Mol. Biol 153, 807-824.

Petrache, H.I., Tristram-Nagle, S., Gawrisch, K., Harries, D., Parsegian, V.A., Nagle, J.F., 2004. Structure and fluctuations of charged phosphatidylserine bilayers in the absence of salt. Biophys. J. 86, 1574-1586.

Pozo Navas, B., Lohner, K., Deutsch, G., Sevcsik, E., Riske, K.A., Dimova, R., Garidel, P., Pabst, G., 2005. Composition dependence of vesicle morphology and mixing properties in a bacterial model membrane system. Biochim. Biophys. Acta 1716, 40-48.

Pressl, K., Jørgensen, K., Laggner, P., 1997. Characterization of the sub-maintransition in distearoylphosphatidylcholine studied by simultaneous small- and wide-angle X-ray diffraction. Biochim. Biophys. Acta 1325, 1-7.

Raghunathan, V.A., Katsaras, J., 1995. Structure of the $\mathrm{L}_{\mathrm{c}^{\prime}}$ phase in a hydrated lipid multilamellar system. Phys. Rev. Lett. 74, 4456-4459.

Raghunathan, V.A., Katsaras, J., 1996. $\mathrm{L}_{\beta^{\prime}}-\mathrm{L}_{\mathrm{c}^{\prime}}$ phase transition in phosphatidylcholine lipid bilayers: a disorder-order transition in two dimensions. Phys. Rev. E 54, 4446-4449.

Rappolt, M., Hodzic, A, Sartori, B., Ollivon, M., Laggner, P., 2008. Conformational and hydrational properties during the $\mathrm{L}_{\beta}-$ to $\mathrm{L}_{\alpha}$ - and $\mathrm{L}_{\alpha}-$ to $\mathrm{H}_{\text {II }}$-phase transition in phosphatidylethanolamine. Chem. Phys. Lipids 154, 46-55.

Rappolt, M., Pabst, G., Rapp, G., Kriechbaum, M., Amenitsch, H., Krenn, C., Bernstorff S., Laggner, P., 2000. New evidence for gel-liquid crystalline phase coexistence in the ripple phase of phosphatidylcholines. Eur. Biophys. J. Biophys. Lett. 29, 125-133.

Rattay, B., Brezesinski, G., Dobner, B., Förster, G., Nuhn, P., 1995. Influence of $\alpha$-branched fatty acid chains on the thermotropic behaviour of racemic $1-O$ hexadecyl-2-acyl-glycero-3-phosphocholines. Chem. Phys. Lipids 75, 81-91.

Ruocco, M.J., Shipley, G.G., 1982a. Characterization of the sub-transition of hydrated dipalmitoylphosphatidylcholine bilayers: kinetic, hydration and structural study. Biochim. Biophys. Acta 691, 309-320.

Ruocco, M.J., Shipley, G.G., 1982b. Characterization of the sub-transition of hydrated dipalmitoylphosphatidylcholine bilayers: X-ray diffraction study. Biochim. Biophys. Acta 684, 59-66.

Schneider, M.F., Zantl, R., Gege, C., Schmidt, R.R., Rappolt, M., Tanaka, M., 2003. Hydrophilic/hydrophobic balance determines morphology of glycolipids with oligolactose headgroups. Biophys. J. 84, 306-313.

Seddon, J.M., Ces, O., Templer, R.H., Mannock, D.A., McElhaney, R.N., 2003. Structure and phase behaviour of synthetic glycolipids. Mol. Cryst. Liq. Cryst. 402, 77-84

Seddon, J.M., Cevc, G., Kaye, R.D., Marsh, D., 1984. X-ray diffraction study of the polymorphism of hydrated diacyl- and dialkylphosphatidylethanolamines. Biochemistry 23, 2634-2644.

Seddon, J.M., Harlos, K., Marsh, D., 1983. Metastability and polymorphism in the ge and fluid bilayer phases of dilauroylphosphatidylethanolamine. J. Biol. Chem. 258, 3850-3854.

Sen, A., Hui, S.-W., Mannock, D.A., Lewis, R.N.A.H., McElhaney, R.N., 1990. Physical properties of glycosyl diacylglycerols. 2. X-ray diffraction studies of a homologous series of 1,2-di-O-acyl-3-O-( $\alpha$-D-glucopyranosyl)-sn-glycerols. Biochemistry 29, 7799-7804.

Serrallach, E.N., De Haas, G.H., Shipley, G.G., 1984. Structure and thermotropic properties of mixed-chain phosphatidylcholine bilayer membranes. Biochemistry 23 , $713-720$. 
Serrallach, E.N., Dijkman, R., De Haas, G.H., Shipley, G.G., 1983. Structure and thermotropic properties of 1,3-dipalmitoyl-glycero-2-phosphocholine. J. Mol. Biol. 170, 155-174.

Sevcsik, E., Pabst, G., Richter, W., Danner, S., Amenitsch, H., Lohner, K., 2008. Interaction of LL-37 with model membrane systems of different complexity: influence of the lipid matrix. Biophys. J. 94, 4688-4699.

Shah, J., Duclos Jr., R.I., Shipley, G.G., 1994. Structure and thermotropic properties of 1-stearoyl-2-acetyl-phosphatidylcholine bilayer membranes. Biophys. J. 66, 1469-1478.

Shah, J., Sripada, P.K., Shipley, G.G., 1990. Structure and properties of mixed-chain phosphatidylcholine bilayers. Biochemistry 29, 4254-4262.

Simon, S.A., Advani, S., McIntosh, T.J., 1995. Temperature dependence of the repulsive pressure between phosphatidylcholine bilayers. Biophys. J. 69, 1473-1483.

Simon, S.A., McIntosh, T.J., Magid, A.D., 1988. Magnitude and range of the hydration pressure between lecithin bilayers as a function of headgroup density. J. Coll. Interface Sci. 126, 74-83.

Sirota, E.B., King, H.E., Singer, D.M., Shao, H.H., 1993. Rotator phases of the normal alkanes - an X-ray scattering study. J. Chem. Phys. 98, 5809-5824.

Slater, J.L., Huang, C., 1987. Scanning calorimetry reveals a new phase transition in L- $\alpha$-dipalmitoylphosphatidylcholine. Biophys. J. 52, 667-670.

Small, D.M., 1986. Handbook of Lipid Research. The Physical Chemistry of Lipids. Plenum Press, New York.

Smith, A.E., 1953. The crystal structure of the normal paraffin hydrocarbons. J. Chem. Phys. 21, 2229-2231.

Stümpel, J., 1981. Kalorimetrie und Röntgenstrukturanalyse an LecithinModellmembranen: der Einfluß von Fettsäurevariationen auf die Membranstruktur, Thesis/Dissertation, Technical University of Braunschweig.

Stümpel, J., Eibl, H., Nicksch, A., 1983. X-ray analysis and calorimetry on phosphatidylcholine model membranes. The influence of length and position of acyl chains upon structure and phase behaviour. Biochim. Biophys. Acta 727, 246-254.

Sun, W.-J., Suter, R.M., Knewtson, M.A., Worthington, C.R., Tristram-Nagle, S., Zhang R., Nagle, J.F., 1994. Order and disorder in fully hydrated unoriented bilayers of gel phase dipalmitoylphosphatidylcholine. Phys. Rev. E 49, 4665-4676.

Sun, W.-J., Tristram-Nagle, S., Suter, R.M., Nagle, J.F., 1996a. Anomalous phase behavior of long chain saturated lecithin bilayers. Biochim. Biophys. Acta 1279, $17-24$.
Sun, W.J., Tristram-Nagle, S., Suter, R.M., Nagle, J.F., 1996b. Structure of gel phase saturated lecithin bilayers: temperature and chain length dependence. Biophys. J. 71, 885-891.

Takahashi, H., Matuoka, S., Kato, S., Ohki, K., Hatta, I., 1991. Electrostatic interaction of poly(L-lysine) with dipalmitoylphosphatidic acid studied by X-ray diffraction. Biochim. Biophys. Acta 1069, 229-234.

Tardieu, A., Luzzati, V., Reman, F.C., 1973. Structure and polymorphism of the hydrocarbon chains of lipids: a study of lecithin-water phases. J. Mol. Biol. 75 711-713.

Tenchov, B., Koynova, R., Rapp, G., 2001. New ordered metastable phases between the gel and subgel phases in hydrated phospholipids. Biophys. J. 80, 1873-1890.

Tenchov, B., Koynova, R., Rappolt, M., Rapp, G., 1999. An ordered metastable phase in hydrated phosphatidylethanolamine: the Y-transition. Biochim. Biophys. Acta 1417, 183-190.

Tristram-Nagle, S., Isaacson, Y., Lyatskaya, Y., Liu, Y., Brummond, K., Katsaras, J., Nagle, J.F., 1999. Polymorphism in myristoylpalmitoylphosphatidylcholine. Chem. Phys. Lipids 100, 101-113.

Tristram-Nagle, S., Liu, Y., Legleiter, J., Nagle, J.F., 2002. Structure of gel phase DMPC determined by X-ray diffraction. Biophys. J. 83, 3324-3326.

Tristram-Nagle, S., Suter, R.M., Sun, W.-J., Nagle, J.F., 1994. Kinetics of subgel formation in DPPC: X-ray diffraction proves nucleation-growth hypothesis. Biochim. Biophys. Acta 1191, 14-20.

Tristram-Nagle, S., Zhang, R., Suter, R.M., Worthington, C.R., Sun, W.J., Nagle, J.F., 1993. Measurement of chain tilt angle in fully hydrated bilayers of gel phase lecithins. Biophys. J. 64, 1097-1109.

Vogel, H., 1978. Physikalisch-chemische Untersuchungen an künstlichen Lipidmembranen, Dissertation, Georg-August-Universität, Göttingen.

Watts, A., Harlos, K., Marsh, D., 1981. Charge-induced tilt in ordered-phase phosphatidylglycerol bilayers. Evidence from X-ray diffraction. Biochim. Biophys. Acta 645, 91-96.

Wilkinson, D.A., Tirrell, D.A., Turek, A.B., McIntosh, T.J., 1987. Tris buffer causes acyl chain interdigitation in phosphatidylglycerol. Biochim. Biophys. Acta 905 447-453.

Zweytick, D., Pabst, G., Abuja, P.M., Jilek, A., Blondelle, S.E., Andrä, J., Jerala, R., Monreal, D., Martinez de Tejada, G., Lohner, K., 2006. Influence of $N$-acylation of peptide derived from human lactoferricin on membrane selectivity. Biochim. Biophys. Acta 1758, 1426-1435. 